\title{
S1-Leitlinie der Deutschen Gesellschaft für Ernährungsmedizin (DGEM) in Zusammenarbeit mit der AKE, der GESKES und der DGfN ${ }^{1}$ Enterale und parenterale Ernährung von Patienten mit Niereninsuffizienz
}

\author{
S1-Guideline of the German Society for Nutritional Medicine (DGEM) in Cooperation with the \\ GESKES, the AKE and the DGFN \\ Enteral and Parenteral Nutrition in Patients with Kidney Disease
}

Autoren

Institute
W. Druml ${ }^{1}$, B. Contzen ${ }^{2}$, M. Joannidis ${ }^{3}$, H. Kierdorf ${ }^{4}$, M. K. Kuhlmann ${ }^{5}$ und das DGEM Steering Committee*

Die Institute sind am Ende des Artikels gelistet.

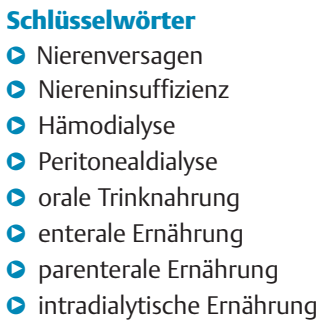

Keywords

acute kidney injury

- chronic kidney disease

end stage renal disease

- hemodialysis

- peritoneal dialysis

- oral nutritional supplements

- enteral nutrition

- parenteral nutrition

- intradialytic nutrition

Bibliografie

DOI http://dx.doi.org/

10.1055/s-0034-1387537

Aktuel Ernahrungsmed 2015;

40: 21-37

(c) Georg Thieme Verlag KG

Stuttgart · New York

ISSN 0341-0501

\section{Korrespondenzadresse Prof. Dr. med. Wilfred DrumI Klinik für Innere Medizin III - Nephrologie, \\ Arbeitsgemeinschaft für \\ Klinische Ernährung \\ Währinger Gürtel 18-20 \\ 1090 Wien, Österreich \\ wilfred.druml@meduniwien.ac.} at

\section{Zusammenfassung \\ $\nabla$}

Fragestellung: Patienten mit Niereninsuffizienz bilden eine sehr heterogene Gruppe von Personen mit unterschiedlichen metabolischen Störungen und Bedarf an Nährstoffen. Zu diesen gehören Patienten mit akutem Nierenversagen (ANV), die rasch zunehmende Zahl von Patienten mit akutauf-chronischem Nierenversagen (A-C-NV), Patienten mit chronischer Niereninsuffizienz (CNI) und Patienten mit terminaler Niereninsuffizienz unter Nierenersatztherapie (Hämodialyse, Peritonealdialyse), jeweils ohne bzw. mit begleitenden Akuterkrankungen. In der vorliegenden Leitlinie sollen die ernährungstherapeutischen Interventionen, welche in der Betreuung aller dieser Patientengruppen eine entscheidende Rolle für Krankheitsverlauf und Prognose spielen, evidenzbasiert dargestellt werden.

Methodik: Die Leitlinie basiert auf den früheren Leitlinien der Deutschen Gesellschaft für Ernährungsmedizin (DGEM, 2003, 2007), der European Society for Parenteral and Enteral Nutrition (ESPEN, 2006, 2009) und der International Society for Renal Nutrition and Metabolism (ISRNM 2008, 2013). Es wurde eine systematische Analyse der Literatur 2006-2014 zur oralen Supplementierung, zur enteralen und parenteralen $\mathrm{Er}$ nährung und intradialytischen Ernährung bei diesen Patientengruppen vorgenommen. Die Empfehlungen wurden innerhalb der Arbeitsgruppe sowie dem DGEM Steering Committee verabschiedet.

Ergebnisse: Zur klinischen Ernährung bei Patienten mit Nierenversagen liegen nur wenige randomisiert-kontrollierte Studien vor, sodass die meisten Empfehlungen Expertenmeinungen darstellen. Die Leitlinie umfasst 15 Aussagen und 27

\footnotetext{
${ }^{1}$ DGfN (Deutsche Gesellschaft für Nephrologie)

* DGEM Steering Committee: Bischoff SC, Lochs H, Weimann A sowie das DGEM-Präsidium
}

\section{Abstract \\ $\nabla$}

Rationale: Renal failure patients comprise an extremely heterogeneous group of subjects with different metabolic patterns and nutritional requirements. These patients comprise patients with acute kidney injury (AKI), the rapidly increasing number of cases with acute-on-chronic renal failure (A-CRF), chronic kidney disease (CKD) and patients on regular renal replacement therapy (RRT) (haemodialysis, peritoneal dialysis), all with or without associated acute disease processes. In the present guideline, nutritional interventions that have a major impact on morbidity and mortality of these patient groups, will be present in an evidence-based manner.

Methods: These recommendations are based on earlier versions issued by the German Society for Nutritional medicine (DGEM, 2003, 2007), the European Society for Parenteral and Enteral Nutrition (ESPEN, 2006, 2009) and the International Society for Renal Nutrition and Metabolism (ISRNM 2008, 2013). A systematic review of the literature was performed for the years 20062014 using the search strategies for oral supplementation, for enteral and parenteral nutrition and intradialytic nutrition for the mentioned patient groups. The statements were finally approved by the working-group and the DGEM steering committee.

Results: There are only a few randomized controlled trials available on nutrition support for renal failure patients and thus, most recommendations are based on limited evidence or they represent clinical consensus points. The guideline includes 15 statements and 27 recommendations. In an introductory chapter, common aspects are covered by 15 statements/recommendations. Nutrition in acutely ill renal patients without requirement of RRT is addressed in 5 statements, nutrition in stable CKD patients without RRT in 5 , nutrition in acutely ill patients on RRT in 9 , 
Empfehlungen, wobei in einem Einleitungskapitel die gemeinsamen Aspekte in 15 Aussagen bzw. Empfehlungen abgehandelt werden. Zu der Ernährung von akut-kranken Patienten ohne Nierenersatztherapie gibt es in dieser Leitlinie 5, zu stabilen CNI-Patient ohne Nierenersatztherapie 5, zu akut-krankem Patient unter Nierenersatztherapie 9 und zu chronisch-malnutrierten Hämodialysepatienten 8 Aussagen bzw. Empfehlungen.

Schlussfolgerung: Ernährungsbehandlung und metabolische Führung spielen eine zentrale Rolle in der Betreuung von Patienten mit Nierenfunktionsstörungen. Dabei müssen die metabolischen Folgen der Nierendysfunktion per se, der Komorbiditäten und begleitenden Akuterkrankungen sowie der ausgeprägte Einfluss der Nierenersatztherapie auf Metabolismus und Nährstoffbilanz berücksichtigt werden. Nährstoffbedarf und Ernährungstherapie können sich grundsätzlich zwischen diesen unterschiedlichen Patientengruppen unterscheiden und sich auch individuell im Krankheitsverlauf ganz wesentlich ändern. Damit erfordern gerade Patienten mit Nierenfunktionsstörungen eine individualisierte Planung, Durchführung und Überwachung der Ernährungstherapie. and nutrition in malnourished chronic dialysis patients in 8 statements/recommendations.

Conclusions: Nutrition support and metabolic management play a central role in the care of patients with renal dysfunction. Both the metabolic consequences of renal dysfunction per se, and of comorbidities and associated acute disease processes and complications, as well as the profound impact of RRT on metabolism and nutrient balances have to be taken into consideration when designing a nutritional program. It should be noted that nutrition needs may differ widely between these heterogeneous groups of patients but also within the same patient in the course of disease. Thus, patients with renal failure require particularly an individualized approach when designing, delivering and monitoring nutritional support.

\section{Abkürzungen \\ A-C-NV Akut-auf-chronisches Nierenversagen \\ ANV Akutes Nierenversagen \\ AS Aminosäuren \\ CAPD chronisch ambulante Peritonealdialyse \\ C-DRM chronic disease-related malnutrition (chronische krankheitsspezifische Mangelernährung) \\ CNI Chronische Niereninsuffizienz \\ ESRD terminale Niereninsuffizienz (CNI-5b) \\ HD Hämodialysetherapie \\ IDEE Intradialytische enterale Ernährung \\ IDOE Intradialytische orale Ernährung \\ IDPE Intradialytische parenterale Ernährung \\ KG Körpergewicht \\ PEM Protein-Energie-Malnutrition \\ PD Peritonealdialyse}

\section{Einführung}

Patienten mit Nierenversagen bilden eine heterogene Gruppe von Personen mit sehr unterschiedlichen metabolischen Störungen und Bedarf an Nährstoffen. Zu diesen gehören

- Patienten mit akutem Nierenversagen (ANV, s. $\bullet$ Tab. 1) oder die rasch zunehmende Zahl von Patienten mit akut-auf-chronischem Nierenversagen (A-C-NV),

- Patienten mit chronischer Niereninsuffizienz (CNI, s.๑ Tab.2),

- Patienten unter Nierenersatztherapie sowie

- Personen, die sich einer Nierentransplantation unterzogen haben,

jeweils ohne oder mit begleitenden Akuterkrankungen.

Nierenfunktionsstörungen selbst gehen mit einem breiten Spektrum an spezifischen metabolischen Störungen einher. Prinzipiell ist das Nierenversagen ein Syndrom, bei dem mehr oder weniger alle physiologischen Funktionen, Stoffwechselwege und Organfunktionen beeinflusst sind.

Eine Nierenfunktionsstörung führt jedoch auch zu grundsätzlichen Modifikationen anderer Erkrankungen, insbesondere von Infektionen. Beispielsweise wird im Falle des ANV, je nach auslö-
Tab. 1 Definition und Stadieneinteilung des akuten Nierenversagens.

\begin{tabular}{|c|c|c|c|}
\hline $\begin{array}{l}\text { Stadium/KDIGO } \\
\text { Rifle }\end{array}$ & $\begin{array}{l}\text { tradit. Bezeich- } \\
\text { nung }\end{array}$ & $\begin{array}{l}\text { Kreatinin- } \\
\text { Kriterium }\end{array}$ & $\begin{array}{l}\text { Diurese- } \\
\text { Kriterium }\end{array}$ \\
\hline ANV $I / R=$ risk & $\begin{array}{l}\text { Nierenschädi- } \\
\text { gung }\end{array}$ & $\begin{array}{l}\text { 1,5-2-mal AW } \\
\text { oder Anstieg } \\
>0,3 \mathrm{mg} / \mathrm{dL}\end{array}$ & $\begin{array}{l}<0,5 \mathrm{ml} / \mathrm{kg} / \mathrm{h} \\
\text { über } \\
6-12 \mathrm{~h}\end{array}$ \\
\hline ANV $2 / 1=$ injury & $\begin{array}{l}\text { Niereninsuffi- } \\
\text { zienz }\end{array}$ & 2-3-mal AW & $\begin{array}{l}<0,5 \mathrm{ml} / \mathrm{kg} / \mathrm{h} \\
\text { über } \\
>12 \mathrm{~h}\end{array}$ \\
\hline ANV $3 / F=$ failure & Nierenversagen & $\begin{array}{l}\text { 3-mal AW oder } \\
\text { Anstieg } \\
>4 \mathrm{mg} / \mathrm{dL} \text { oder } \\
\text { Beginn Nieren- } \\
\text { ersatztherapie }\end{array}$ & $\begin{array}{l}<0,3 \mathrm{ml} / \mathrm{kg} / \mathrm{h} \\
\text { über } \\
>24 \mathrm{~h} \text { oder } \\
\text { Anurie } \\
>12 \mathrm{~h}\end{array}$ \\
\hline
\end{tabular}

nach KDIGO; Serumkreatinin in mg/dL, ANV=akutes Nierenversagen, AW=Ausgangswert

Tab. 2 Die Stadien der chronischen Niereninsuffizienz.

\begin{tabular}{|lll|}
\hline Stadium & trad. Bezeichnung & eGFR* $\mathbf{~ I I / m i n ~}$ \\
\hline CNI 1 & Nierenschädigung & $\geq 90$ \\
\hline CNI 2 & Niereninsuffizienz & $89-60$ \\
\hline CNI 3a & kompensierte Retention & $59-45$ \\
\hline CNI 3b & kompensierte Retention & $30-44$ \\
\hline CNI 4 & dekompensierte Retention & $29-15$ \\
\hline CNI 5 & terminale Niereninsuffizienz & $<15$ \\
& mit oder ohne HD & \\
* berechnete glomeruläre Filtrationsrate nach Standard-Formeln (z. B. Crockoft-Gault, \\
MDRD, CKD-EPI)
\end{tabular}

sender Grundkrankheit, ein proinflammatorischer, prooxidativer und hyperkataboler Zustand induziert, der einen unabhängigen Einfluss auf Krankheitsverlauf und Mortalität ausübt.

Neben den metabolischen Störungen, die durch die Dysfunktion der Nieren verursacht werden, sind auch die verschiedenen Nierenersatzverfahren mit ausgeprägten Änderungen des Stoffwechsels und der Nährstoffbilanzen verbunden.

Zusätzlich wird der Stoffwechsel und der Nährstoffbedarf auch durch jene Erkrankung beeinflusst, die zur Nierendysfunktion (beim ANV) bzw. zum Intensivaufenthalt geführt hat. Zudem 
können gleichzeitig andere Organfunktionsstörungen und Komplikationen, wie Infektionen, eintreten, die den Stoffwechsel modifizieren.

Daher muss beachtet werden, dass der Nährstoffbedarf und die Ernährungstherapie sich grundsätzlich zwischen diesen sehr unterschiedlichen Patientengruppen unterscheiden, sich jedoch auch bei einem Patienten selbst im Krankheitsverlauf ganz wesentlich ändern können. Damit erfordern Patienten mit Nierenfunktionsstörungen noch viel mehr als andere Patientengruppen eine sehr individualisierte Planung und Durchführung der Ernährungstherapie.

Durch die Störung der Nierenfunktion und die damit einhergehenden grundsätzlichen Änderungen des Stoffwechsels besteht nicht nur eine eingeschränkte Toleranz gegenüber Volumen und Elektrolyten, sondern auch gegenüber zahlreichen Nährstoffen, sodass das Risiko der Ausbildung von Stoffwechselentgleisungen massiv erhöht ist. Daher erfordern Patienten mit Nierenversagen eine wesentlich engere Überwachung (,Monitoring“) der Ernährungstherapie als andere Patientengruppen.

Bei Patienten mit Niereninsuffizienz beinhalten die Ernährungsziele neben einer Reduktion der urämischen Toxizität auch die Prävention der Progression der Nierenerkrankung. Beim ANV ist eine Förderung der renalen Reparaturprozesse durch ernährungsmedizinische Konzepte zumindest intendiert.

Bei Patienten mit Nierenversagen wurden nur sehr wenige systematische Studien zur künstlichen Ernährung durchgeführt. Zudem sind einige von diesen Studien vor vielen Jahren unter Bedingungen erfolgt, die nicht dem derzeitigen Stand des Wissens und der Praxis der Ernährungstherapie entsprechen. Studien mit „harten“ Endpunkten, wie Intensiv- oder Krankenhausaufenthaltsdauer, Komplikationshäufigkeit, Erholung der Nierenfunktion oder Überleben, sind nur vereinzelt verfügbar. Moderne Untersuchungen sind meist sekundäre Analysen von Subgruppen der Patienten mit ANV aus größeren Studien.

Mit dieser sehr „dünnen“ Datenlage können die meisten hier gemachten Aussagen und Empfehlungen nicht auf qualitativ hochwertige, randomisierte, prospektive Untersuchungen gestützt werden, sondern sind meist Expertenmeinungen; ein Umstand, den sich diese Patientengruppen durchaus mit andern Indikationen der Ernährungstherapie bei akut-kranken Patienten teilt [1]. Sicherlich ist die künstliche Ernährung der verschiedenen Gruppen von Patienten mit Nierenfunktionsstörungen nicht grundsätzlich unterschiedlich von jener bei anderen Krankheitszuständen. Jedoch muss in der Planung und Durchführung der Ernährungstherapie dieses breite Spektrum an metabolischen Störungen und Änderung des Nährstoffbedarfs berücksichtigt werden und eine Koordinierung mit der Nierenersatztherapie erfolgen.

In dieser Leitlinie sollen keine allgemeinen Aussagen zur künstlichen Ernährung gemacht werden, sondern nur die spezifischen Aspekte der künstlichen Ernährung von Patienten mit Nierenfunktionsstörungen zusammengefasst werden (Übersichten $[2-4])$.

\section{Methodik}

$\nabla$

Die vorliegende Leitlinie basiert auf den früheren Leitlinien der DGEM $(2003,2007)[5,6]$, der ESPEN $(2006,2009)[2,7]$ bzw. auch der ISRNM $(2008,2013)[8,9]$. Sie fasst die Aspekte zur enteralen Ernährung und parenteralen Ernährung in einer Leitlinie zusammen und richtet sich an alle Berufsgruppen, die nephrologische Patienten mit enteraler und/oder parenteraler Ernährung versorgen. Sie soll ihnen konkrete Handlungsempfehlungen für den Einsatz und Umgang mit künstlicher Ernährung bei der heterogenen Patientengruppe mit Nierenversagen geben.

Die verschiedenen Patientengruppen mit Nierenversagen: Personen mit Nierenversagen bilden eine sehr heterogene Gruppe von Patienten, bei denen sich Stoffwechsel und Nährstoffbedarf grundsätzlich unterscheiden.

- Patienten mit akutem Nierenversagen (ANV) oder akut-aufchronischem Nierenversagen (A-C-NV)

- Patienten mit chronischer Niereninsuffizienz ohne Notwendigkeit der Nierenersatztherapie (CNI-Stadium 3-5)

- akut kranke und chronisch kranke Patienten unter Nierenersatztherapie: Hämodialyse (HD), kontinuierliche Nierenersatztherapie, verschiedene Formen der Peritonealdialyse (PD)

- Patienten nach Nierentransplantation (nicht besprochen in diesen Empfehlungen)

Aus einer metabolischen und ernährungstherapeutischen Sicht können folgende Patientengruppen unterschieden werden, die metabolische und ernährungstherapeutische Gemeinsamkeiten aufweisen und daher im Folgenden gemeinsam besprochen werden sollen. Vorangestellt werden einige allgemeine Bemerkungen, die alle Gruppen von Patienten mit Nierenversagen betreffen.

- Akut-kranke Patienten mit ANV, mit A-C-NV oder mit chronischer Niereninsuffizienz (CNI 3-5) und begleitende AkutErkrankungen ohne Notwendigkeit der Nierenersatztherapie

- Stabile Patienten mit chronischer Niereninsuffizienz ohne begleitende Akut-Erkrankungen (CNI 3-5) und ohne Notwendigkeit der Nierenersatztherapie

- Akut-kranke Patienten mit ANV, mit A-CNV (AKIN-3) oder terminaler Niereninsuffizienz (CNI-5; ESRD) unter Nierenersatztherapie (inklusive Intensivpatienten)

- der chronische CNI-5 Patient mit chronischer krankheitsspezifischer Mangelernährung unter Nierenersatztherapie (ESRD), mit oder ohne interkurrente Begleiterkrankungen Die Leitlinie wurde von einer Expertengruppe aus Internisten mit dem Schwerpunkt Nierenerkrankungen erarbeitet. Zu Beginn der Leitlinienarbeit wurde eine Literatursuche über die Pubmed-Suchoberfläche der National Library of Medicine durchgeführt. Folgende Schlüsselwörter wurden verwendet:

"enteral nutrition" OR "parenteral nutrition" OR "nutrition support" OR "metabolism" OR "feeding tube"

in Verbindung mit folgenden krankheitsassoziierten Schlüsselbegriffen:

„intradialytic nutrition“ OR "acute kidney injury” OR "acute-onchronic renal failure" OR "chronic kidney disease" OR "renal replacement therapy" OR "hemodialysis therapy" OR "peritoneal dialysis"

Es wurden Originalarbeiten, Leitlinien, Meta-Analysen, systematische Übersichtsarbeiten, randomisiert-kontrollierte Studien und Beobachtungsstudien seit 1970 bis 31.7.2014 eingeschlossen. Berücksichtigt wurden ausschließlich themenrelevante englische oder deutsche Publikationen sowie Publikationen, die im Volltext erhältlich waren.

Von den Arbeitsgruppen wurden die Empfehlungen anhand dieser Literatur erarbeitet, diskutiert und gegebenenfalls modifiziert. Es wurde darauf geachtet, dass die Empfehlungen spezifisch und eindeutig formuliert sind.

Die Empfehlungen wurden in der Arbeitsgruppe sowie im DGEM-Präsidium einstimmig verabschiedet. 
Des Weiteren wurde die Leitlinie folgenden Fachgesellschaften zur Autorisierung vorgelegt:

- Österreichische Arbeitsgemeinschaft für klinische Ernährung (AKE)

- Gesellschaft für Klinische Ernährung der Schweiz (GESKES)

- Deutsche Gesellschaft für Nephrologie (DGfN)

Die Leitlinie (AWMF-Registernummer: 073-009) ist gültig von Januar 2015 bis Januar 2020. Spätestens nach 5 Jahren wird die Leitlinie einer erneuten Revision unterzogen. Neu erscheinende wissenschaftliche Erkenntnisse werden von den Mitgliedern der Arbeitsgruppe beobachtet. Falls notwendig, wird die DGEM eine Überarbeitung und Aktualisierung einzelner Themenkomplexe vorzeitig vornehmen lassen. Aktualisierungen werden gesondert in Form eines Addendums publiziert.

\section{Grundsätzliche Gemeinsamkeiten der nephrologi- schen Patientengruppen}

3.1 Übt eine Niereninsuffizienz einen Einfluss auf den Stoffwechsel aus, der in der Planung der Ernährungstherapie berücksichtigt werden sollte?

\section{Statement 1:}

Alle Formen der Niereninsuffizienz verursachen zusätzlich zu den Störungen des Volumen-, Elektrolyt- und Säure-Basen-Haushalts eine grundsätzliche Änderung des „milieu interieur“ mit spezifischen Auswirkungen auf den Protein- und Aminosäuren-, den Kohlenhydrat- und Fettstoffwechsel und können je nach Art der akuten Begleiterkrankung eine proinflammatorische Reaktion und Depletion des antioxidativen Systems verursachen.

Kommentar: Grundsätzlich führt jede Niereninsuffizienz zu einer Beeinträchtigung zahlreicher physiologischer Reaktionen, Stoffwechselwege und endokriner Funktionen ( $\bullet$ Tab.3). Die Proteinsynthese ist vermindert, der Proteinabbau stimuliert, die Glukoseutilisation beeinträchtigt, der Fettabbau gehemmt. Zudem finden sich auch hochgradige Störungen im Stoffwechsel von Vitaminen und Spurenelementen, das antioxidative Potenzial ist massiv beeinträchtigt $[10,11]$.

Tab. 3 Die wichtigsten spezifischen metabolischen Störungen, die durch eine Niereninsuffizienz induziert werden.

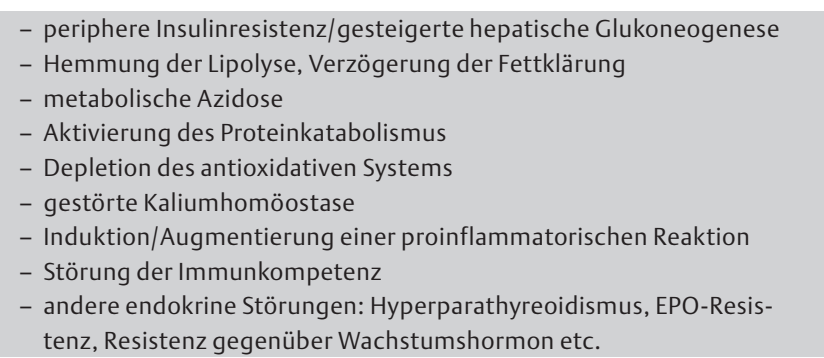

Bei Patienten mit fortgeschrittener CNI kommt es durch die Triade von gesteigertem Proteinabau, inadäquater Proteinsynthese und inadäquater spontaner oraler Aufnahme von Proteinen und Energiesubstraten zu einem hohen Risiko der Ausbildung einer Protein-Energie-Malnutrition (PEM-= protein engery malnutrition), die nach neuerer Terminologie „Chronische krankheitsspe- zifische Mangelernährung“ (C-DRM=chronic disease-related malnutrition) genannt wird (s. Kapitel CNI) [12].

Zusätzlich muss beachtet werden, dass der Stoffwechsel bei Patienten mit Niereninsuffizienz häufig durch interkurrente Erkrankungen bzw. im Falle des ANV durch die zugrunde liegende Erkrankung und im Krankheitsverlauf auftretende Komplikationen und zusätzliche Organversagen beeinflusst werden kann [4]. Schließlich üben auch die verschiedenen Nierenersatzverfahren einen grundlegenden Einfluss auf Stoffwechsel und Nährstoffbilanzen aus (s. $\odot$ Tab.6).

\subsection{Hat die Niereninsuffizienz einen relevanten Einfluss auf den Energiestoffwechsel bzw. den Energiebedarf der Patienten?}

\section{Statement 2:}

Die Niereninsuffizienz selbst übt keinen wesentlichen Einfluss auf den Energiehaushalt aus. Der Energiebedarf wird bei Niereninsuffizienz vorwiegend durch zugrunde liegende Erkrankungen, begleitende Komplikationen oder auch durch das Ausmaß von Inflammation und Komorbiditäten bestimmt.

Kommentar: Bei stoffwechselstabilem, therapeutisch gut kompensiertem Nierenversagen ohne Komplikationen und Begleiterkrankungen ist der Energiestoffwechsel nur unwesentlich beeinflusst, möglicherweise im Sinne eines „urämischen Hypometabolismus“ sogar vermindert [13].

Bei bettlägrigen akut-kranken Patienten entspricht die empfohlene Energiezufuhr jener bei anderen Akuterkrankungen (s. DGEM-Leitlinie „Klinische Ernährung in der Intensivmedizin“). Bei mobilen Patienten mit CNI und hohem Risiko der Ausbildung einer PEM/C-DRM sollte jedoch in Abhängigkeit von der körperlichen Aktivität eine höhere Zufuhr (35 kcal/kg KG/Tag) angestrebt werden [2].

\subsection{Ist die enterale Ernährung auch für Patienten mit Niereninsuffizienz die zu bevorzugende Form der künstlichen Ernährung?}

\section{Statement 3:}

Die enterale Ernährung ist die bevorzugte Form der künstlichen Ernährung auch für akut und chronisch kranke Patienten mit Niereninsuffizienz. Bereits kleine Mengen enteral verabreichter Nährstoffe können die Schutzfunktion des Darmes unterstützen.

Kommentar: Obwohl aus einer historischen Perspektive die meisten Studien zur künstlichen Ernährung bei Nierenversagen mit parenteraler Ernährung vorgenommen wurden, kann kein Zweifel darüber bestehen, dass die enterale Ernährung auch bei niereninsuffizienten Patienten die Methode der ersten Wahl der künstlichen Ernährung darstellt [14].

Generell sollte man parenterale und enterale Ernährung nicht als konkurrierende, sondern sich gegenseitig ergänzende Methoden ansehen, da es gerade bei Patienten mit Niereninsuffizienz oft unmöglich ist, eine bedarfsdeckende Ernährung auf enteralem Weg vorzunehmen. In diesen Fällen kann eine ergänzende bzw. totale parenterale Ernährung notwendig werden.

Beim ANV könnte die enterale Ernährung zudem spezifische Vorteile aufweisen, indem - wie zumindest im Tierexperiment ge- 
zeigt wurde - durch eine enterale Nahrungszufuhr die renale Perfusion und auch die Funktion gesteigert werden [15]. Eine enterale Ernährung war zumindest in Kohortenstudien einer der Faktoren, der mit einer verbesserten Prognose assoziiert war [16].

\subsection{Welche Art von Sondennahrung soll bei Patienten mit Niereninsuffizienz verwendet werden?}

\section{Empfehlung 1:}

Im Allgemeinen sollten bei akut-kranken Patienten mit Niereninsuffizienz (wie für andere Akutpatienten) hochmolekulare Standard-Diäten für die enterale Ernährung verwendet werden. Spezifische nierenadaptierte Präparate können in Einzelfällen bzw. bei langer Therapiedauer die metabolische Führung erleichtern. Bei stabilen Patienten mit chronischer Niereninsuffizienz können spezifische Präparate Vorteile aufweisen (s. Unterkapitel).

Kommentar: Für Patienten mit Niereninsuffizienz wurden 3 Gruppen von enteralen Ernährungspräparaten entwickelt, für Patienten mit akutem Nierenversagen gibt es bislang keine speziellen Präparate $[4,17]$ :

1. Chemisch definierte Pulver-Diäten: Diese protein- und elektrolytreduzierten Präparate wurden im Sinne einer proteinreduzierten Diät für Patienten mit CNI ohne Notwendigkeit der Nierenersatztherapie entwickelt und sind z.T. noch auf dem Markt. Diese Präparate sind ernährungsphysiologisch unvollständig und daher für die komplette enterale Ernährung heute obsolet.

2. Nährstoffdefinierte, hochmolekulare Flüssigdiäten (NDD) für Patienten mit CNI ohne Nierenersatztherapie: Diese wurden als oral bilanzierte Diäten (OBD) entwickelt und können auch zur enteralen Ernährung eingesetzt werden. Sie sind protein-, kalium- und phosphatreduziert. Manche haben Zusätze, wie Carnitin oder Histidin.

3. Nährstoffdefinierte, hochmolekulare Flüssigdiäten für Patienten mit CNI unter Dialysetherapie: Diese wurden als oral bilanzierte Diäten (OBD) entwickelt und können auch zur enteralen Ernährung eingesetzt werden. Sie sind proteinreich, aber gleichzeitig kalium- und phosphatreduziert. Manche haben Zusätze, wie Carnitin oder Histidin.

Für Akutpatienten werden weltweit Standard-NDD wie für nicht niereninsuffiziente Patienten verwendet [14].

Zusammenfassend sind speziell für die Niereninsuffizienz-Präparate für die orale Supplementierung entwickelt worden, die auch in der enteralen Ernährung eingesetzt werden können.

Bei Akutpatienten hingegen werden weltweit Standard-NDD wie für andere Patientengruppen eingesetzt $[2,4]$.

Für den Einsatz von Präparaten der Immunonutrition liegen für Patienten mit Niereninsuffizienz keine systematischen Studien vor; daher sollten diese auch nicht eingesetzt werden.

Sondennahrungen enthalten nach einer EU-Richtlinie den Tagesbedarf an Mikronährstoffen von Gesunden. Beachtet sollte werden, dass insbesondere Patienten unter Nierenersatztherapie einen erhöhten Bedarf an Mikronährstoffen haben können. Dies gilt insbesondere für wasserlösliche Vitamine, Vitamin D und Selen.

\subsection{Sollen Sondennahrungen für Patienten mit Niereninsuffizienz Ballaststoffe enthalten?}

\section{Empfehlung 2:}

Für die enterale Ernährung von Patienten mit Niereninsuffizienz sollten ballaststoffhaltige Produkte verwendet werden.

Kommentar: Dieser Punkt wird speziell erwähnt, da eine zunehmende Zahl von Studien gezeigt hat, dass Ballaststoffe bei Patienten mit Niereninsuffizienz spezifisch günstige Effekte induzieren können. Dies betrifft einerseits die verminderte Bildung von urämischen Toxinen, die gesteigert Adsorption und Ausscheidung von Toxinen und auch einen signifikanten antiinflammatorischen Effekt [18].

\subsection{Gibt es bei Patienten mit Niereninsuffizienz spezielle Probleme, die eine enterale Ernährung limitieren können?}

\section{Statement 4:}

Eine Beeinträchtigung der Nierenfunktion führt zu Störungen der gastrointestinalen Motilität und der Magenentleerung. Zudem ist die Absorption verschiedener Nährstoffe, insbesondere von Fett, beeinträchtigt.

Kommentar: Durch diese Änderungen der intestinalen Funktionen wird die enterale Ernährung beeinträchtigt, weshalb diese im Vergleich zu Patienten ohne Nierenversagen oft nur verzögert aufgebaut werden kann [19].

\subsection{Sollen bei Patienten mit Niereninsuffizienz und intestinaler Intoleranz Prokinetika eingesetzt werden?}

\section{Empfehlung 3:}

Wegen der Beeinträchtigung der intestinalen Motilität bei Niereninsuffizienz sollten in der enteralen Ernährung frühzeitig Prokinetika eingesetzt werden.

Kommentar: Wie bei anderen Patientengruppen sollten frühzeitig Prokinetika eingesetzt werden. Systematische Untersuchungen für Patienten mit Niereninsuffizienz fehlen, jedoch wurden wie auch bei anderen Intensivpatienten, bei diesen Metoclopramid und Erythromycin eingesetzt [20].

\subsection{Wenn bei akut-kranken Patienten mit Niereninsuf-} fizienz eine parenterale Ernährung notwendig wird, sollten dann spezielle Aminosäurenlösungen verwendet werden?

\section{Empfehlung 4:}

Für die parenterale Ernährung niereninsuffizienter Patienten können Normallösungen oder spezielle „Nephro“-Lösungen verwendet werden. Inkomplette Aminosäurelösungen, die nur essenzielle Aminosäuren enthalten, sollen nicht verwendet werden.

Kommentar: Prinzipiell werden/wurden 3 Arten von Aminosäurenlösungen in der parenteralen Ernährung von Patienten mit Niereninsuffizienz verwendet [4]. 
1. Lösungen von ausschließlich essenziellen Aminosäuren nach dem für die Therapie der CNI entwickelten Konzeptes einer proteinarmen Diät. Diese Lösungen sind ernährungstechnisch unvollständig, haben eine unausgewogene Zusammensetzung, können schwerwiegende Störungen (wie eine Hyperammoniämie) induzieren und sind somit als obsolet anzusehen.

2. Spezielle, für das Nierenversagen entwickelte „Nephro“-Lösungen, die ein komplettes Aminosäurenmuster aufweisen, an den geänderten Stoffwechsel adaptiert sind und z.T. auch Aminosäuren enthalten, die bei Niereninsuffizienz krankheitsbedingt essenziell werden können (z. B. Tyrosin, wegen seiner geringen Wasserlöslichkeit als Dipeptid). Diese Lösungen haben metabolische Vorteile, Studien mit „harten“ Endpunkten liegen jedoch nicht vor [21,22].

3. Normallösungen, wie sie auch bei Patienten ohne Niereninsuffizienz eingesetzt werden, werden von den meisten Gruppen bevorzugt [14].

Heute sollen nur Lösungen verwendet werden, die essenzielle und nicht essenzielle Aminosäuren entweder in einem Standardmuster oder in einer spezifisch an den bei Niereninsuffizienz gestörten Metabolismus orientierten Zusammensetzung enthalten. In Anbetracht neuerer Untersuchungen zu Funktionen von Aminosäuren, die weit über den Proteinhaushalt hinausgehen, wie intrazelluläres Signalling im mTOR-Weg, dürften spezielle Lösungen in Zukunft wieder verstärkt diskutiert werden [23].

3.9 Wenn bei akut-kranken Patienten mit Niereninsuffizienz eine parenterale Ernährung notwendig wird, sollte auch Glutamin zugeführt werden?

\section{Empfehlung 5:}

Bei Patienten mit Niereninsuffizienz ohne Nierenersatztherapie sollte in der Ernährung kein Glutamin zugesetzt werden, unter Nierenersatztherapie kann Glutamin verabreicht werden.

Kommentar: Obwohl Glutamin die Nierenfunktion verbessern kann und zumindest im Tierexperiment nephroprotektive Wirkungen aufweist, gibt es keine speziell renale Indikation für die Verabreichung von Glutamin [24]. Systematische Untersuchungen zu Glutamin bei Patienten mit ANV sind nicht durchgeführt worden. Allerdings gibt es Sekundäranalysen von anderen Studien zu Glutamin, die speziell Patienten mit Niereninsuffizienz auswerten (s. Akutpatienten).

Glutamin sollte bei Patienten mit Niereninsuffizienz ohne Nierenersatztherapie nach der neuesten Untersuchung von Heyland und insbesondere nach der Sekundäranalyse jener Patienten mit Nierenfunktionsstörungen, nicht verabreicht werden $[25,26]$. Wenn bei Patienten unter Nierenersatztherapie eine Indikation für Glutamin aus anderen Gründen vorliegt, kann Glutamin der Ernährung zugesetzt werden (s. Empfehlung 22).

\subsection{Wenn bei Patienten mit Niereninsuffizienz eine parenterale Ernährung notwendig wird, sollten auch} Fettemulsionen verwendet werden?

\section{Empfehlung 6:}

Trotz der Beeinträchtigung von Hydrolyse und Fettklärung kann Fett dosisadaptiert in der künstlichen Ernährung von Patienten mit Niereninsuffizienz verwendet werden, wobei die Plasmatriglyzeride kontrolliert werden sollen.
Kommentar: Die Änderungen des Fettstoffwechsels bei Niereninsuffizienz (Hemmung der Lipolyse) sollten nicht dazu führen, kein Fett in der parenteralen Ernährung einzusetzen [27]. Jedoch sollte die Infusion durch Kontrolle der Plasmatriglyzeride überwacht und bei Anstieg über $400 \mathrm{mg} / \mathrm{dL}$ die Fettzufuhr vermindert oder beendet werden.

Die heute empfohlene Fettdosis von ca. $1 \mathrm{~g}$ Fett/kg KG/Tag führt selten zu einer Überschreitung der Triglyzeridgrenze (s. DGEMLeitlinie „Klinische Ernährung in der Intensivmedizin“).

\subsection{Wenn intravenöses Fett verwendet wird, welche Art von Fettemulsionen sollen eingesetzt werden?}

Empfehlung 7:

Auch bei Patienten mit Nierenversagen sollten moderne, PUFAreduzierte Fettemulsionen verwendet werden.

Kommentar: Bei verschiedenen Nierenerkrankungen (IgA-Nephritis, CNI, ANV, Z.n. Nierentransplantation) wurde versucht, durch den Einsatz von Fischöl (sowohl als Bestandteil der Ernährungstherapie, aber auch im Sinne einer Pharmakonutrition) und dadurch vermittelte immunmodulatorische und hämodynamische Effekte, die Nierenfunktion und den Krankheitsverlauf günstig zu beeinflussen [28].

Bislang fehlen Studien, die zeigen, dass die Verwendung von Fettemulsionen mit einem verminderten Gehalt an mehrfach ungesättigten Omega-6-Fettsäuren (durch Austausch von Sojabohnenöl durch Kokosöl [MCT], durch Olivenöl oder Fischöl), um damit potenzielle proinflammatorische Nebeneffekte zu reduzieren, bei Patienten mit chronischer Nierenerkrankung positive Auswirkungen zeigt. Dennoch wird bei Patienten mit Niereninsuffizienz, so wie auch bei den anderen Patientengruppen, der Einsatz der modernen PUFA-reduzierten Mischemulsionen empfohlen.

In einer häufig zitierten Arbeit über Fischöl in der Ernährungstherapie bei akuter Pankreatitis wurde über eine signifikante Reduktion der Dauer der Nierenersatztherapie berichtet $(p<0,05)$ [29]. Hier muss ein Fehler in der statistischen Auswertung vorliegen, da nur 3 Patienten in der Kontrollgruppe und nur 2 Patienten in der Verumgruppe ein ANV hatten und damit eine statistisch gestützte Aussage wohl nicht möglich ist.

\subsection{Erfordert die künstliche Ernährung bei Patienten mit Niereninsuffizienz ein spezielles Monitoring?}

\section{Empfehlung 8:}

Patienten mit Niereninsuffizienz sollten wegen der geänderten Toleranz gegenüber Volumen und Elektrolyte und den vielfältigen Änderungen des Stoffwechsels einem engmaschigen Monitoring hinsichtlich der künstlichen Ernährung unterzogen werden.

Kommentar: Bei Niereninsuffizienz ist der Elektrolyt- und Volumenhaushalt gestört, sodass rasch Entgleisungen auftreten können. Durch zusätzliche Stoffwechselstörungen und Retention von Stoffwechselendprodukten erhöht sich die Gefahr der Ausbildung ernährungsbedingter Komplikationen. Daher muss die Ernährungstherapie von Patienten mit Niereninsuffizienz streng überwacht werden. Die Volumen- und Elektrolytbilanz (insbesondere von Kalium und Phosphat) sollte dabei täglich neu beurteilt werden. Wegen des geänderten Stoffwechsels müssen 
Blutzucker und Serumtriglyzeride regelmäßig bestimmt werden.

Bei Patienten ohne Nierenersatztherapie muss durch Monitoring von Harnstoff/BUN die Proteinzufuhr adaptiert werden.

Ein langsamer Ernährungsaufbau sollte die Überwachung erleichtern und die Ausbildung von Komplikationen vermindern.

\subsection{Wie sollte die Glukosekontrolle bei Niereninsuffi- zienz gehandhabt werden?}

\section{Empfehlung 9:}

Bei Nierenpatienten unter einer künstlichen Ernährung sollte eine Blutglukose von $<180 \mathrm{mg} / \mathrm{dL}$ aufrechterhalten werden.

Kommentar: Eine Niereninsuffizienz führt per se zu einer Beeinträchtigung der Glukoseverwertung [30]. Andererseits ist eine Hyperglykämie sowohl akut als auch chronisch ein Risikofaktor für die Ausbildung einer Nierenschädigung. Daher sollte - um Hyperglykämien zu vermeiden - eine Ziel-Blutglukose-Konzentration von $<180 \mathrm{mg} / \mathrm{dL}(\sim 10 \mathrm{mmol} / \mathrm{L})$ (also unterhalb der Nierenschwelle für Glukose) aufrechterhalten werden [31]. Damit dies tatsächlich erreicht wird, sollte eine Zielglukose von 150 $\mathrm{mg} / \mathrm{dL}$ (ca. $8 \mathrm{mmol} / \mathrm{L}$ ) angestrebt werden. Unbedingt vermieden sollte aber eine Hypoglykämie.

3.14 Ab welcher Beeinträchtigung der Nierenfunktion sollte eine Ernährungstherapie adaptiert werden?

\section{Statement 5:}

Beim akuten Nierenversagen (ANV) treten metabolische Änderungen ab dem Stadium RIFLE-Stadium I/AKIN-Stadium 2 bzw., wenn eine Nierenersatztherapie notwendig wird (RIFLE F, AKINStadium III), auf, bei chronischer Niereninsuffizienz (CNI) dann, wenn die glomeruläre Filtrationsrate (GFR) unter $60 \mathrm{~mL} / \mathrm{min} /$ $1,73 \mathrm{~m}^{2}$ (bzw. $45 \mathrm{~mL} / \mathrm{min} / 1,73 \mathrm{~m}^{2}$ ) bei Patienten $>65$ Jahre (CNI-Stadium 3-5) abfällt.

\section{Kommentar:}

Bei Patienten mit ANV und A-CNV (Definition ANV s. KDIGO [2012]) [32]: RIFLE-Stadium $R$ und I/AKIN-Stadien I und II

In diesen frühen Stadien des ANV stehen zunächst Maßnahmen im Vordergrund, um die Nierenfunktion zu stabilisieren bzw. eine Progression des Nierenversagens zu verhindern. Dies beinhaltet auch metabolische und ernährungstherapeutische Maßnahmen, wie das einer ausgeglichenen Elektrolytbilanz, Vermeidung einer Hyperglykämie oder Ausbildung einer Malnutrition. RILFE-Stadium F/AKIN-Stadium III

In den späteren Stadien RIFLE I-F, AKIN 2 - 3 sollten die metabolischen Besonderheiten des Nierenversagens bzw. auch der Nierenersatztherapie berücksichtigt werden. In diesem Stadium des ANV wird bei Intensivpatienten heute meist frühzeitig mit der Nierenersatztherapie begonnen, um die systemischen Auswirkungen des ANV zu minimieren, die Volumen- und Elektrolytbilanz aufrechtzuerhalten und die hämodynamischen und respiratorischen Funktionen zu unterstützen.

Bei Patienten mit CNI: Bei Patienten mit CNI entstehen die für die künstliche Ernährung relevanten Stoffwechselstörungen ab dem Stadium CNI-3b (=eGFR $<45 \mathrm{~mL} / \mathrm{min})$. Beachtet muss werden, dass sich Nährstoffbedarf und Ernährungstherapie im CNI-Stadi- um 5 beim Übergang zur Nierenersatztherapie grundsätzlich ändern.

\subsection{Wie sollte der Ernährungsaufbau bei Patienten mit Niereninsuffizienz erfolgen?}

\section{Empfehlung 10:}

Bei allen Patienten mit Niereninsuffizienz sollte der Ernährungsaufbau über 3 bis 5 Tage erfolgen, um metabolische Entgleisungen zu vermeiden und die Verwertung der Substrate überprüfen zu können.

Kommentar: Wegen der beeinträchtigten gastrointestinalen Funktionen, der verminderten metabolischen Toleranz verschiedener Substrate und dem hohen Risiko von Elektrolytentgleisungen, sollte ein langsamer Ernährungsaufbau über 3-5 Tage vorgenommen werden, um einen überhöhten Harnstoff- bzw. BUNAnstieg und andere metabolische Entgleisungen, wie eine Hyperglykämie oder Hypertriglyzeridiämie bzw. Elektrolyt-Imbalanzen, zu vermeiden.

\section{Der akut-kranke Patient mit akutem Nierenversagen (ANV), akut-auf-chronischem Nierenversagen (A-C-NV) oder chronischer Niereninsuffizienz (CNI) mit akuten Begleiterkrankungen ohne Notwendigkeit einer Nierenersatztherapie \\ $\nabla$}

4.1 Was ist der Nährstoffbedarf dieser akut-kranken Patientengruppe mit Niereninsuffizienz ohne Notwendigkeit der Nierenersatztherapie?

\section{Statement 6:}

Im Gegensatz zu Patienten mit stabiler chronischer Niereninsuffizienz (CNI) entspricht der Substratbedarf von akut-kranken nephrologischen Patienten jenem von anderen akut-kranken Patienten.

Kommentar: In $\bullet$ Tab. 4 ist der Nährstoffbedarf zusammengefasst, wobei Richtwerte angegeben sind. Der Substratbedarf muss individuell an den Patienten adaptiert werden, da das Krankheitsgeschehen und auch der Verlauf des ANV sehr variabel sein können.

Cave: Patienten mit CNI ohne akute Begleiterkrankungen haben einen geänderten Substratbedarf.

\subsection{Wie hoch sollte die Protein- bzw. Aminosäuren- zufuhr sein?}

\section{Empfehlung 11:}

Akut-kranke Patienten mit Niereninsuffizienz sollten je nach Katabolismus und individueller Toleranz 0,8-1,2 g/kg KG/Tag an Proteinen bzw. Aminosäuren erhalten.

Kommentar: Bei diesen Patienten sollte, wenn die Notwendigkeit einer Nierenersatztherapie vermieden werden soll, die Proteinund Aminosäurenzufuhr mit niedriger Rate begonnen werden $(\sim 0,5 \mathrm{~g} / \mathrm{kg} \mathrm{KG} / \mathrm{Tag})$ und unter Kontrolle der Harnstoff- bzw. BUN Werte über 3-5 Tage gesteigert werden. Veränderungen der Se- 
Tab. 4 Nährstoffbedarf von akut-kranken Patienten mit Niereninsuffizienz ohne Nierenersatztherapie*

\begin{tabular}{|c|c|c|}
\hline Energie & $20-25$ & kcal/kg KG/Tag \\
\hline Aminosäuren/Protein & $0,8-1,2^{* *}$ & $\mathrm{~g} / \mathrm{kg} \mathrm{KG/Tag}$ \\
\hline Kohlenhydrate & $3,0-4,0$ & $\mathrm{~g} / \mathrm{kg} \mathrm{KG} / \mathrm{Tag}$ \\
\hline Fett & $0,8-1,2^{* * *}$ & $\mathrm{~g} / \mathrm{kg} \mathrm{KG} / \mathrm{Tag}$ \\
\hline L-Carnitin ${ }^{1}$ & 0,5 & $\mathrm{~g} / \mathrm{Tag}$ \\
\hline $\begin{array}{l}\text { wasserlösliche Vita- } \\
\text { mine }^{2}\end{array}$ & $\begin{array}{l}\text { (Kombinationspräpa- } \\
\text { rate) }\end{array}$ & $\begin{array}{l}\text { 1-mal Tagesbedarf } \\
\text { (RDA) }\end{array}$ \\
\hline fettlösliche Vitamine ${ }^{2}$ & $\begin{array}{l}\text { (Kombinationspräpa- } \\
\text { rate) }\end{array}$ & $\begin{array}{l}\text { 1-mal Tagesbedarf } \\
\text { (RDA) }\end{array}$ \\
\hline Spurenelemente ${ }^{2}$ & $\begin{array}{l}\text { (Kombinationspräpa- } \\
\text { rate) }\end{array}$ & $\begin{array}{l}\text { 1-mal Tagesbedarf } \\
\text { (RDA) }\end{array}$ \\
\hline Elektrolyte $^{2}$ & \multicolumn{2}{|c|}{$\begin{array}{l}\text { eine Phosphat-/Kaliumrestriktion ist bei Akut- } \\
\text { erkrankungen meist nicht notwendig }\end{array}$} \\
\hline
\end{tabular}

* Individualisierung! Der Bedarf kann zwischen Patienten sehr unterschiedlich sein, sich aber auch im Krankheitsverlauf grundsätzlich ändern; ** in Abhängigkeit des Katabolimus und der individuellen Toleranz; ${ }^{* * *}$ Monitoring der Plasmatriglyzeride erforderlich; ${ }^{1}$ optional; ${ }^{2}$ enterale Diätpräparate enthalten den empfohlenen Tagesbedarf

rum-Harnstoff-Konzentration können zur Steuerung des Ernährungsaufbaus verwendet werden; der Anstieg der Harnstoffkonzentration sollte $50 \mathrm{mg} / \mathrm{dL}$ (bzw. BUN $\sim 25 \mathrm{mg} / \mathrm{dL}$ ) pro Tag nicht übersteigen.

Obwohl heute die Plasmakonzentrationen von „Retentionsparametern“ bei Akutpatienten nicht die einzige Indikation zur Einleitung einer Nierenersatztherapie darstellen, sollte die Harnstoffkonzentration Werte von 180-200 mg/dL (BUN 80-100 $\mathrm{mg} / \mathrm{dL}$ ) nicht übersteigen.

In vielen akut-klinischen Szenarien kann es aber wichtiger sein, eine adäquate Ernährung vorzunehmen und falls sich die metabolische Situation verschlechtert, bei Bedarf eine Nierenersatztherapie zu beginnen.

Cave: Im Gegensatz zum stabilen CNI sollte bei akut-kranken Patienten mit Nierenversagen keine anhaltende Proteinrestriktion vorgenommen werden.

4.3 Welche anderen metabolischen Faktoren sollten in der Ernährungstherapie dieser Patienten berücksichtigt werden?

\section{Statement 7:}

Die Niereninsuffizienz geht mit verschiedenen Änderungen des Stoffwechsels einher, welche auch bei der Verordnung einer Ernährungstherapie Berücksichtigung finden sollten. Dazu gehören:

- Prävention/Therapie der metabolischen Azidose

- Ausgleich einer Hypovitaminose-D-Gabe von (aktivem) Vitamin $\mathrm{D}\left(\sim 1 \mu \mathrm{g}\right.$ Calzitriol oder $1000 \mathrm{U} / \mathrm{d}$ Vitamin $\left.\mathrm{D}_{3}\right)$

- Vermeidung einer anhaltenden Hyper- oder Hypophosphatämie

- Beachtung der Kaliumbilanz

Kommentar: Wie oben dargestellt, induziert eine Niereninsuffizienz ein sehr komplexes metabolisches Umfeld, das bei Planung, Durchführung und Überwachung der Ernährungstherapie berücksichtigt werden sollte [12].
4.4 Welche Art von Sondennahrungen sollten bei akutkranken Patienten mit Niereninsuffizienz ohne Nierenersatztherapie verwendet werden?

\section{Empfehlung 12:}

Für akut-kranke Patienten mit Niereninsuffizienz ohne Nierenersatztherapie sollten wie für andere Akutpatienten hochmolekulare Standard-Ernährungspräparate für die enterale Ernährung verwendet werden. Spezifische nierenadaptierte Präparate können in Einzelfällen bzw. bei langer Therapiedauer die metabolische Führung erleichtern.

Kommentar: Für Patienten mit chronischer Niereninsuffizienz ohne Nierenersatztherapie wurden spezielle enterale Ernährungspräparate entwickelt (s. Kapitel 3), die das Konzept einer proteinreduzierten Diät verfolgen, aber für katabole Patienten mit Niereninsuffizienz nicht geeignet sind [4].

Bei akut kranken Patienten mit Niereninsuffizienz stellen Hyperkaliämie und Hyperphosphatämie kein häufiges Problem dar, sodass eine Elektrolytrestriktion meist nicht notwendig ist. Bei mehrwöchiger Therapiedauer, insbesondere bei Patienten mit CNI, können dagegen spezielle Präparate die Ernährungstherapie erleichtern [17].

4.5 Welche Art von Aminosäurenlösungen sollten in der parenteralen Ernährung akut-kranker Patienten mit Niereninsuffizienz ohne Nierenersatztherapie verwendet werden?

\section{Empfehlung 13:}

Für akut-kranke Patienten mit Niereninsuffizienz ohne Nierenersatztherapie sollten Standard-Aminosäuren-Lösungen verwendet werden. Spezifische Lösungen können in Einzelfällen bzw. bei langer Therapiedauer die metabolische Führung erleichtern.

Kommentar: Für akut-kranke Patienten werden meist StandardAminosäuren-Lösungen empfohlen. Gerade bei Patienten, bei denen eine Nierenersatztherapie nicht geplant oder gewünscht ist, können spezielle Nephrolösungen Vorteile aufweisen und bei adäquater Aminosäurenzufuhr die Harnstoffsteigerung minimieren.

\section{Der stabile Patient mit chronischem Nierenversagen ohne Notwendigkeit einer Nierenersatztherapie (=CNI-3 bis 5)}

Diese nicht akut-kranke Patientengruppe mit CNI ohne Nierenersatztherapie ist sicherlich eine nicht häufige Indikation für eine künstliche Ernährung. Bei Patienten mit manifester Malnutrition kann eine orale Gabe von oral bilanzierten Diäten (OBD) indiziert sein [12, 17]; bei pflegebedürftigen oder neurologisch beeinträchtigten Patienten kann eine länger dauernde enterale Ernährung notwendig werden. 


\subsection{Wie hoch ist der Nährstoffbedarf bei Patienten mit chronischer Niereninsuffizienz ohne Notwendigkeit einer Nierenersatztherapie?}

\section{Statement 8:}

Die Nährstoffzufuhr von stabilen Patienten mit chronischer Niereninsuffizienz (CNI) ohne Nierenersatztherapie kann in der Regel standardisiert erfolgen ( $\bullet$ Tab.5).

Tab. 5 Nährstoffbedarf von stabilen Patienten mit CNI ohne Nierenersatztherapie*.

\begin{tabular}{|lll|}
\hline Energie** $^{*}$ & $30-35$ & $\mathrm{kcal} / \mathrm{kg} \mathrm{KG} / \mathrm{Tag}$ \\
\hline Protein/Aminosäuren $^{*}$ & $0,6-0,8$ & $\mathrm{~g} / \mathrm{kg} \mathrm{KG} / \mathrm{Tag}$ \\
& $(-1,0)$ & \\
\hline Kohlenhydrate & $3,0-4,0$ & $\mathrm{~g} / \mathrm{kg} \mathrm{KG} / \mathrm{Tag}$ \\
\hline Fett & $0,8-1,2$ & $\mathrm{~g} / \mathrm{kg} \mathrm{KG} / \mathrm{Tag}$ \\
\hline L-Carnitin $^{1}$ & 0,5 & $\mathrm{~g} / \mathrm{Tag}$ \\
\hline wasserlösliche Vitamine $^{2}$ & $\begin{array}{l}\text { (Kombinations- } \\
\text { präparate) }\end{array}$ & $\begin{array}{l}1-\mathrm{mal} \text { Tagesbedarf } \\
\text { (RDA) }\end{array}$ \\
\hline fettlösliche Vitamine & $\begin{array}{l}\text { (Kombinations- } \\
\text { präparate) }\end{array}$ & $\begin{array}{l}1-\mathrm{mal} \text { Tagesbedarf } \\
\text { (RDA) }\end{array}$ \\
\hline Spurenelemente $^{2}$ & $\begin{array}{l}\text { (Kombinations- } \\
\text { präparate) }\end{array}$ & $\begin{array}{l}1-\mathrm{mal} \text { Tagesbedarf } \\
\text { (RDA) }\end{array}$ \\
\hline Elektrolyte $^{2}$ & $\begin{array}{l}\text { eine Phosphat-/Kaliumrestriktion ist bei } \\
\text { stabilen CNI meist notwendig }\end{array}$ \\
\hline Flüssigkeit* & & \\
\hline
\end{tabular}

* Der Bedarf kann sich durch Akuterkrankungen grundsätzlich ändern; ** in Abhängigkeit der körperlichen Aktivität; ${ }^{1}$ in einigen Ernährungspräparaten enthalten, optional; ${ }^{2}$ enterale Ernährungspräparate, die den empfohlenen Tagesbedarf enthalten, Vitamin D s.u.

Kommentar: Klinisch stabile Patienten mit CNI, die keine Nierenersatztherapie benötigen, können in Abhängigkeit vom Ausmaß der Niereninsuffizienz einen speziellen Nährstoffbedarf haben ( $\bullet$ Tab.5). Bei interkurrenten Akuterkrankungen oder Hospitalisierungen kann sich dieser Nährstoffbedarf grundsätzlich ändern (s. Kapitel 4,॰ Tab.4)..

Bei Patienten mit chronischer Niereninsuffizienz wird eine Proteinzufuhr von $0,6-0,8 \mathrm{~g} / \mathrm{kg} \mathrm{KG} / \mathrm{Tag}$ empfohlen, wobei die optimale Zufuhr vom Ausmaß der körperlichen Aktivität bestimmt wird. Bei Bettlägerigkeit bzw. Pflegebedürftigkeit sinkt der Energiebedarf.

\subsection{Wie hoch ist die optimale Protein- bzw. Amino- säurenzufuhr bei stabilen Patienten mit CNI?}

\section{Empfehlung 14:}

Stabile Patienten mit chronischer Niereninsuffizienz (CNI) sollten je nach Katabolismus und individueller Toleranz 0,6-0,8 g/kg KG/ Tag an Protein/Aminosäuren erhalten.

Kommentar: Da die wesentlichsten urämischen Toxine aus dem Proteinstoffwechsel abgeleitet sind, kann eine proteinreduzierte Ernährung die urämische Toxizität vermindern. Auch wird einer proteinreduzierten Ernährung ein progressionshemmender Effekt auf den Verlauf chronischer Nierenerkrankungen zugeschrieben. Dies kann auch zu einer Verzögerung des Zeitpunkts der Dialyseeinleitung beitragen [33]. Aus diesem Grund wird bei Patienten mit CNI seit vielen Jahren eine diätetische Eiweißrestriktion empfohlen, wobei die optimale Höhe der Zufuhr nicht genau definiert ist. Eine Proteinzufuhr $<0,6 \mathrm{~g} / \mathrm{kg} \mathrm{KG} /$ Tag solle bei dieser nicht-akut-kranken Patientengruppe allerdings vermieden werden, um die Entwicklung einer Mangelernährung zu verhindern [2].

Bei diesen Patienten soll die Notwendigkeit der Nierenersatztherapie vermieden werden und daher die Protein- und Aminosäurenzufuhr langsam begonnen und gesteigert und anhand des Anstiegs von Harnstoff/BUN adaptiert werden.

\subsection{Sollte bei Patienten mit CNI eine Alkalisierungs- therapie vorgenommen werden?}

\section{Empfehlung 15:}

Bei stabilen Patienten mit chronischer Niereninsuffizienz (CNI) soll eine Alkalisierungstherapie mit einem Ziel-Serum-Bikarbonat $>22 \mathrm{mmol} / \mathrm{L}$ vorgenommen werden.

Kommentar: Die ungünstigen metabolischen Folgen einer urämischen Azidose sind extensiv dokumentiert. In mehreren epidemiologischen Studien findet sich eine Korrelation von Azidose und Mortalität [34]. Ein Ausgleich der Azidose, d.h. eine Alkalisierungstherapie, kann den Proteinkatabolismus und Muskelverlust vermindern, die Muskelkraft steigern, den Knochenstoffwechsel (MBD) verbessern, das Wachstum bei urämischen Kindern beschleunigen und eventuell auch die Progression der Nierenerkrankung verzögern $[35,36]$.

Die Alkalisierung kann durch Infusionen von Natriumbikarbonat, durch die orale/enterale Gabe von Natriumbikarbonat und/oder Natriumzitrat, bei oraler Ernährung auch durch eine obst-/gemüsereiche Kost erzielt werden [37].

5.4 Welche anderen metabolischen Faktoren sollten in der Ernährungstherapie von Patienten mit CNI berücksichtigt werden?

\section{Statement 9:}

Das Nierenversagen geht mit verschiedenen Änderungen des Stoffwechsels einher, die auch im Rahmen einer Ernährungstherapie Berücksichtigung finden sollten. Bei betroffenen Patienten ist deshalb insbesondere von Bedeutung:

- Beachtung der Flüssigkeitszufuhr

- Kontrolle der Natriumbilanz

- Beachtung der Kaliumbilanz

- frühzeitige Behandlung einer Hyperphosphatämie

- Gabe von (aktivem) Vitamin D ( 1 $\mu$ g Calcitriol oder $1000 \mathrm{U} / \mathrm{d}$ Vitamin $\mathrm{D}_{3}$ )

Kommentar: Nierenversagen induziert ein sehr komplexes metabolisches Umfeld, das in der Planung/Durchführung/Überwachung der künstlichen Ernährungstherapie berücksichtigt werden sollte (s. auch Kapitel 3, ○ Tab.3). Die angeführten Punkte gehören zum Standardmanagement des CNI [38]. 
5.5 Welche Art von Sondennahrungen sollten bei nicht akut-kranken Patienten mit CNI ohne Nierenersatztherapie verwendet werden?

\section{Empfehlung 16:}

Bei stabilen Patienten mit chronischer Niereninsuffizienz (CNI) können spezielle Ernährungspräparate, die für nicht-dialysepflichtige Patienten entwickelt worden sind, verwendet werden, weil sie die metabolische Führung erleichtern.

Kommentar: Wie im Kapitel 3 dargestellt, wurden für stabile nicht-dialysepflichtige Patienten mit CNI spezielle Diäten entwickelt, die proteinreduziert sind, einen geringeren Gehalt an Kalium und Phosphat aufweisen und verschiedene Zusätze, wie Histidin oder Carnitin beinhalten $[4,17]$.

Wenn allerdings akute interkurrente Erkrankungen bestehen, können Standardpräparate eingesetzt werden (bzgl. Ballaststoffe s. Kapitel 3).

\section{Der akut-kranke Patient mit ANV, A-C-NV und CNI mit interkurrenten Akuterkrankungen, die eine Nierenersatztherapie benötigen}

\section{1 Üben Nierenersatzverfahren einen relevanten} Einfluss auf Stoffwechsel und Nährstoffbilanzen aus?

\section{Statement 10:}

Alle Formen der Nierenersatztherapie üben einen fundamentalen Einfluss auf Stoffwechsel und Nährstoffbilanzen aus, die in der Planung der Ernährungstherapie berücksichtigt werden müssen.

Kommentar: Sowohl intermittierende als auch kontinuierliche Nierenersatzverfahren einschließlich der Peritonealdialyse üben einen grundlegenden Einfluss auf Stoffwechsel und Nährstoffbilanzen aus ( Tab.6). Extrakorporale Therapieverfahren induzieren zudem eine inflammatorische Reaktion und verstärken die Inflammation der Grunderkrankung (SIRS etc.) [4, 39, 40].

\subsection{Wie hoch ist der Nährstoffbedarf dieser Patienten- gruppe unter einer Nierenersatztherapie?}

\section{Statement 11:}

Die Nährstoffzufuhr von akut-kranken Patienten mit Nierenversagen unter Nierenersatztherapie kann in der Regel standardisiert erfolgen ( Tab.7).

Kommentar: Akut-kranke Patienten mit ANV/A-CKD und CNI, die eine Nierenersatztherapie benötigen, haben ein systemisches inflammatorisches Syndrom (SIRS) und einen aktivierten Proteinkatabolismus. Der Nährstoffbedarf ähnelt dem anderer akutkranker (Intensiv-)Patienten (s. DGEM-Leitlinie „Klinische Ernährung in der Intensivmedizin") und wird durch die Nierenersatztherapie modifiziert ( Tab.6) [2, 4, 40, 41].

Bezüglich des Energiebedarfs hatten Fiaccadori et al. eine kontrollierte Studie vorgenommen, wobei eine Gruppe von Patienten mit ANV $30 \mathrm{kcal} / \mathrm{kg} \mathrm{KG/Tag}$, die andere $40 \mathrm{kcal} / \mathrm{kg}$ KG/Tag erhalten hatten [42]. Für die höhere Energiezufuhr war kein Vorteil nachweisbar, insbesondere auch nicht für den Proteinstoffwech-

\begin{tabular}{l} 
Tab. 6 Metabolische Nebenwirkungen der Nierenersatztherapie. \\
Intermittierende Hämodialyse/Hämodiafiltration (HD/HDF) \\
Verlust wasserlöslicher Moleküle \\
- Aminosäuren \\
- wasserlösliche Vitamine \\
- L-Carnitin etc. \\
\hline Aktivierung des Proteinkatabolismus \\
- Verlust von Aminosäuern \\
- Verlust von Proteinen und Blut \\
- Induktion einer inflammatorischen Reaktion/Freisetzung von \\
Zytokinen (IL-1ß, TNF- $\alpha$ etc.) \\
\hline Erhöhung der Bildung von ROS \\
\hline Hitzeverlust (=Verlust von Energie) \\
\hline Extrakorporale Blut-/Membraninteraktion \\
(Aktivierung von zellulären Elementen [Granulozyten, Thrombozyten], \\
Induktion/Aktivierung von Mediatorkaskaden, inflammatorische \\
Reaktion, Stimulation des Proteinkatabolismus) \\
\hline Peritonealdialyse (PD) \\
\hline Protein- und Aminosäurenverluste in das Dialysat \\
\hline Verlust von proteingebundenen Substanzen mit dem Dialysat \\
(z. B. Spurenelemente) \\
\hline Absorption von Glukose aus dem Dialysat \\
\hline Induktion einer systemischen Inflammation \\
\hline Erhöhung des intraabdominellen Druckes \\
\hline kontinuierliche Nierenersatzverfahren \\
\hline Hitzeverlust (=Verlust von Energie) \\
\hline exzessive Zufuhr von Substraten (Laktat, Zitrat, Glukose etc.) \\
\hline Verlust von Nährstoffen (Aminosäuren, Vitamine, Selen etc.) \\
\hline Verlust von Elektrolyten (Phosphat, Magnesium) \\
\hline Elimination von Peptiden/Proteinen (Hormonen, Mediatoren?, Albumin) \\
\hline extrakorporale Blut-/Membraninteraktion (s.o.) \\
\hline
\end{tabular}

Tab.7 Nährstoffbedarf von akut-kranken Patienten mit Nierenversagen unter Nierenersatztherapie*.

\begin{tabular}{|c|c|c|}
\hline Energie & $20-25$ & kcal/kg KG/Tag \\
\hline $\begin{array}{l}\text { Protein/Aminosäu- } \\
\text { ren** }\end{array}$ & $1,2-1,5(\max 1,8)$ & $\mathrm{g} / \mathrm{kg} \mathrm{KG/Tag}$ \\
\hline Kohlenhydrate & $3,0-4,0$ & $\mathrm{~g} / \mathrm{kg} \mathrm{KG} / \mathrm{Tag}$ \\
\hline Fett & $0,8-1,2^{* * *}$ & $\mathrm{~g} / \mathrm{kg} \mathrm{KG} / \mathrm{Tag}$ \\
\hline L-Carnitin ${ }^{1}$ & 0,5 & $\mathrm{~g} / \mathrm{Tag}$ \\
\hline $\begin{array}{l}\text { wasserlösliche Vita- } \\
\text { mine }^{2}\end{array}$ & $\begin{array}{l}\text { (Kombinationspräpara- } \\
\text { te) }\end{array}$ & $\begin{array}{l}\text { 2-mal Tages- } \\
\text { bedarf (RDA) }\end{array}$ \\
\hline fettlösliche Vitamine ${ }^{2}$ & $\begin{array}{l}\text { (Kombinationspräpara- } \\
\text { te) }\end{array}$ & $\begin{array}{l}\text { 1-mal Tages- } \\
\text { bedarf (RDA) }\end{array}$ \\
\hline Spurenelemente ${ }^{2}$ & $\begin{array}{l}\text { (Kombinationspräpara- } \\
\text { te) }\end{array}$ & $\begin{array}{l}\text { 1-mal Tagesbe- } \\
\text { darf (RDA) }\end{array}$ \\
\hline Elektrolyte $^{2}$ & \multicolumn{2}{|c|}{$\begin{array}{l}\text { eine Phosphat-/Kaliumrestriktion ist bei Akut- } \\
\text { erkrankungen meist nicht notwendiq }\end{array}$} \\
\hline
\end{tabular}

* Individualisierung! Der Bedarf kann zwischen Patienten sehr unterschiedlich sein, sich aber auch im Krankheitsverlauf grundsätzlich ändern; ** in Abhängigkeit des Katabolimus und der individuellen Toleranz; ${ }^{* * *}$ Monitoring der Plasmatriglyzeride erforderlich; ${ }^{1}$ in manchen Diäten enthalten, optional (s. u.); ${ }^{2}$ evtl. geänderter Bedarf an Vitamin D und Selen, enterale Diätpräparate enthalten den empfohlenen Tagesbedarf

sel, jedoch war die Rate an metabolischen Komplikationen erhöht (Hyperglykämie, Insulinbedarf, Hypertriglyzeridämie). Heute wird für diese Patientengruppe die gleiche Energiezufuhr wie für andere Intensivpatienten empfohlen. Unter kontinuierlicher Nierenersatztherapie mit Zitratantikoagulation kommt es durch die Zitratzufuhr zu einer schwer quantifizierbaren zusätzlichen Energieaufnahme. 
6.3 Wie hoch ist die optimale Protein- bzw. Aminosäurenzufuhr bei akut-kranken Patienten mit Niereninsuffizienz unter Nierenersatztherapie?

\section{Empfehlung 17:}

Akut-kranke Patienten mit akutem Nierenversagen (ANV), akutauf-chronischem Nierenversagen (A-C-NV) oder chronische Niereninsuffizienz (CNI) unter Nierenersatztherapie sollten je nach Ausmaß des Katabolismus und individueller Toleranz 1,2-1,6 (max. $1,8 \mathrm{~g}) \mathrm{g} / \mathrm{kg} \mathrm{KG} / \mathrm{Tag}$ an Protein/Aminosäuren erhalten.

Kommentar: Dies ist die umstrittenste Frage der künstlichen Ernährung bei Patienten mit ANV und A-C-NV. Die früher in Analogie zum CNI empfohlene Proteinrestriktion sollte nicht vorgenommen werden. Ziel ist eine optimale Ernährung, während die Nierenersatztherapie nach Bedarf vorgenommen werden soll. Für eine von australischen Autoren auf Basis von methodisch unzulänglichen Untersuchungen empfohlene deutlich höhere Proteinzufuhr von $2,5 \mathrm{~g} / \mathrm{kg} \mathrm{KG} / \mathrm{Tag}$, die die urämische Toxizität verstärken und eine Hyperammoniämie indizieren kann [43, 44], gibt es derzeit keine Begründung.

Verschiedene Untersuchungen haben nachgewiesen, dass der Proteinkatabolismus bei dieser akut-kranken Patientengruppe bei ca. $1,5 \mathrm{~g} / \mathrm{kg} \mathrm{KG} /$ Tag liegt $[3,45]$. Daher wird derzeit eine $\mathrm{Zu}-$ fuhr von 1,4-1,6g/kg KG/Tag empfohlen, die bei hyperkatabolen Patienten unter Nierenersatztherapie bis max. $1,8 \mathrm{~g} / \mathrm{kg} \mathrm{KG} / \mathrm{Tag}$ betragen kann.

Der Verlust von Aminosäuren beträgt während einer Hämodialyse ca. $2 \mathrm{~g} /$ Stunde. Bei der kontinuierlichen Nierenersatztherapie kann ein Richtwert von 0,2 g/L Filtrat bzw. Dialysat angenommen werden [39].

In einer Sekundäranalyse der RENAL-Studie konnte kein Einfluss der Höhe der Proteinzufuhr auf die Überlebensrate nachgewiesen werden [46]. Allerdings lagen in dieser Studie Proteinzufuhr und Energiezufuhr weit unter der empfohlenen Rate.

Ob eine erhöhte Zufuhr von Aminosäuren einen nephroprotektiven Effekt (durch Steigerung der renalen Perfusion; „renale Reservekapazität“) entfalten kann, bleibt umstritten [47]. Eine Pilotstudie aus Australien hat eine Zufuhr von 1,0 gegenüber 2,0 g AS/kg KG/Tag verglichen (Doig 2014, in Publikation). In dieser Studie waren allenfalls Surrogatparameter durch die höhere $\mathrm{Zu}$ fuhr verbessert (z.B. Verminderung der Serum-Kreatinin-Konzentration). Eine große randomisierte Studie ist in Planung.

6.4 Welche Art von Sondennahrungen sollten bei akutkranken Patienten mit Niereninsuffizienz unter Nierenersatztherapie verwendet werden?

\section{Empfehlung 18:}

Für akut-kranke Patienten mit Niereninsuffizienz unter Nierenersatztherapie sollten hochmolekulare Standarddiäten

für die enterale Ernährung verwendet werden. Spezifische an die Nierenfunktion adaptierte Präparate können in Einzelfällen bzw. bei langer Therapiedauer die metabolische Führung erleichtern.

Kommentar: Für akut-kranke Patienten mit Niereninsuffizienz unter Nierenersatztherapie werden heute enterale StandardNDD wie für nicht nierenkranke Personen eingesetzt [14].

Die für stabile Dialysepatienten entwickelten speziellen enteralen NDD (proteinbetont, elektrolytreduziert, spezielle Zusätze, s.
Kapitel 2) können bei nicht mehr katabolen Patienten, in der Erholungsphase oder bei chronischen Intensivpatienten Vorteile in der Durchführung der Ernährungstherapie aufweisen [17].

\subsection{Ist bei akut-kranken Patienten mit Niereninsuffizienz unter Nierenersatztherapie eine Phosphatrestriktion notwendig?}

\section{Empfehlung 19:}

Bei akut-kranken Patienten mit Niereninsuffizienz unter Nierenersatztherapie soll der Serumphosphatspiegel überwacht und bei Bedarf eine ausreichende Phosphatsubstitution sichergestellt werden, weil diese Patienten ein hohes Risiko aufweisen, eine Hypophosphatämie zu entwickeln.

Kommentar: Im Gegensatz zum Patienten mit CNI haben akutkranke Patienten unter Nierenersatztherapie ein hohes Risiko eine Hypophosphatämie zu entwickeln, wobei eine der Ursachen der therapiebedingte Phosphatverlust darstellt. Dies tritt sowohl unter einer intermittierenden Hämodialyse [48] als auch unter einer kontinuierlichen Nierenersatztherapie auf [49] und hat Auswirkungen auf Krankheitsverlauf und Prognose. Auf eine ausreichende Phosphatsubstitution muss geachtet werden. Für die kontinuierliche Nierenersatztherapie stehen heute phosphathaltige Substitutionslösungen zur Verfügung [50].

6.6 Wie sollte die Vitaminsubstitution bei akut-kranken Patienten mit Niereninsuffizienz unter Nierenersatztherapie erfolgen?

\section{Statement 12:}

Akut-kranke Patienten mit Niereninsuffizienz unter Nierenersatztherapie haben einen erhöhten Bedarf an wasserlöslichen Vitaminen.

Kommentar: Akut-kranke Patienten mit Niereninsuffizienz unter Nierenersatztherapie haben eine ausgeprägte Depletion des antioxidativen Systems $[10,11]$ und einen erhöhten Bedarf an wasserlöslichen Vitaminen, was durch den erhöhten Verlust durch die Nierenersatztherapie [51, 52], aber auch durch einen erhöhten metabolischen Umsatz bei Akuterkrankungen bedingt ist. Besonders für Thiamin sind schwerwiegende Mangelzustände beschrieben worden [53].

Wenn auch exakte Bedarfszahlen nicht verfügbar sind, wird heute aus pragmatischen Gründen die Zufuhr des doppelten Tagesbedarfs von wasserlöslichen Vitaminen empfohlen.

Auch mit der enteralen Ernährung wird mit den derzeit verfügbaren Ernährungspräparaten lediglich der Tagesbedarf von Gesunden gedeckt. Daher sollte auch unter enteraler Ernährung eine höhere Zufuhr erfolgen.

Bezüglich der fettlöslichen Vitamine finden sich bei Patienten mit ANV mit Ausnahme des Vitamin K massiv verminderte Spiegel [54]. Derzeit wird die Substitution in Höhe der RDA empfohlen [2]. Der Bedarf an Vitamin D bzw. auch an aktivem Calcitriol ist nicht definiert. Wieweit bei diesen Patienten die renale Aktivierung von Vitamin D erhalten ist, ist unbekannt. Jüngste Untersuchungen sprechen für einen Bedarf von >1000 U/Tag [55].

Toxische Erscheinungen von fettlöslichen Vitaminen wurden bei der Substitution von Vitamin A bei Kindern mit ANV berichtet [56]. 


\subsection{Was sollte bei der Spurenelementsubstitution beachtet werden?}

\section{Empfehlung 20:}

Bei akut-kranken Patienten mit Niereninsuffizienz unter Nierenersatztherapie soll - mit Ausnahme von Selen - die Substitution des Tagesbedarfs (RDA) an Spurenelementen erfolgen. Selen sollte in höherer Dosierung als die RDA für Gesunde erfolgen.

Kommentar: Exakte Bedarfszahlen sind bei dieser Patientengruppe auch für Spurenelemente nicht verfügbar, weshalb die für andere Akutpatienten empfohlene Zufuhr in Höhe der RDAs für diese Patienten gültig ist.

Eine mögliche Ausnahme ist Selen, wobei gezeigt wurde, dass mit der kontinuierlichen Nierenersatztherapie mehr als der empfohlene Tagesbedarf eliminiert wird, weshalb eine höhere Zufuhr indiziert ist (z.B. $300 \mu \mathrm{g} / \mathrm{Tag}$ ) [57].

Cave: Es gibt keinen Hinweis dafür dass eine überhöhte „pharmakologische“ Dosierung inklusive Selen bei diesen Patienten positive Effekte induzieren kann. Bei Patienten mit Nierenversagen sind die wichtigsten Regulatoren der Spurenelement-Homöostase, nämlich die intestinale Resorption und renale Elimination, gestört, sodass die Gefahr der Induktion von toxischen Erscheinungen besteht.

6.8 Wenn eine enterale Ernährung quantitativ nicht ausreichend vorgenommen werden kann, wann sollte mit einer supplementierenden oder totalen parenteralen Ernährung begonnen werden?

\section{Empfehlung 21:}

Wenn eine enterale Ernährung nicht möglich ist, sollte eine parenterale Ernährung früh $(<24 \mathrm{~h})$ begonnen werden. Wenn eine enterale Ernährung nicht zeitgerecht aufgebaut werden kann, sollte mit einer supplementären oder totalen parenteralen Ernährung nach 2-4 Tagen begonnen werden.

Kommentar: Wenn eine enterale Ernährung kontraindiziert oder nicht möglich ist, sollte früh $(\leq 24 \mathrm{~h})$ mit einer parenteralen Ernährung begonnen werden, wobei die Ernährung langsam aufgebaut werden muss (s. Kapitel 3).

Wenn eine enterale Ernährung trotz Einsatz von Prokinetika nicht zeitgerecht aufgenommen werden kann, sollte eine parenterale Ernährung ab Tag 2-4 begonnen werden [58].

Für einen frühen Beginn einer supplementierenden enteralen Ernährung spricht bei Patienten unter Nierenersatztherapie der persistierende therapiebedingte Nährstoffverlust.

In einer sekundären Analyse der EPaNIC-Studie von den Patienten mit ANV hatte allerdings ein früher Beginn einer parenteralen Ernährung keinen Vorteil gegenüber einem späteren Beginn [59]. Andererseits hatte ein früher Beginn einer parenteralen Ernährung in der EARLY-PN-Studie moderate Vorteile gegenüber einem späten Beginn, wobei allerdings eine Subanalyse der Nierenpatienten bislang fehlt [60].
6.9 Wie sollte eine parenterale Nährlösung zusammengesetzt sein und wie sollte die PE vorgenommen und überwacht werden?

Siehe Kapitel 3 zu Überlegungen zur Zusammensetzung, der verwendeten Aminosäurenlösungen und Fettemulsionen etc., den Ernährungsaufbau und das Monitoring der parenteralen Ernährung.

Heute sollten industrielle vorgefertigte Lösungen, die Aminosäuren, Glukose und Fettemulsion enthalten (3-Kammer-Beutel) eingesetzt werden, denen vor Verwendung je nach individuellem Erfordernis die wasserlöslichen Vitamine (2-mal RDA), fettlöslichen Vitamine und die erforderlichen Elektrolyte inklusive Phosphat zugesetzt werden.

\subsection{Sollten diese Patienten mit der PE auch Glutamin erhalten?}

\section{Empfehlung 22:}

Bei kritisch-kranken Patienten mit Niereninsuffizienz unter Nierenersatztherapie kann Glutamin im Rahmen einer parenteralen Ernährung verabreicht werden.

Kommentar: Die Mitglieder dieser Konsensusgruppe sehen keine Kontraindikation gegen eine i.v. Gabe von Glutamin bei kritischkranken Patienten unter Nierenersatztherapie. In einer Post-hocAnalyse der Studie von Griffith et al. überlebten nur 4 von $24 \mathrm{~Pa}-$ tienten mit ANV ohne Glutaminzusatz, aber 14 von 23 Patienten mit ANV mit Glutamin $(\mathrm{p}<0,02)$ [61].

Auch in der Sekundäranalyse der REDOXS-Studie war die Mortalität bei Patienten, die einer Nierenersatztherapie unterzogen wurden, in der Glutamingruppe nicht erhöht [26].

\section{Der mangelernährte Patient unter chronischer Nie- renersatztherapie (Hämodialyse, Peritonealdialyse) $\nabla$}

Eine chronische krankheitsspezifische Mangelernährung (CDRM), früher auch Protein-Energie-Malnutrition (PEM) oder Protein-Energie-Wasting (PEW) genannt, findet sich häufig bei Patienten mit fortgeschrittener chronischer Niereninsuffizienz und insbesondere bei Patienten unter einer chronischen Nierenersatztherapie. Die ISRNM hat für diese Patientengruppe eine Definition des C-DRM vorgeschlagen [8] und Empfehlungen zur Therapie veröffentlicht [12].

Die C-DRM präsentiert eine Kombination verschiedener metabolischer und ernährungsassoziierter Störungen und ist eng verbunden mit Krankheitsverlauf, der Rate an Hospitalisierungen und der Prognose der Patienten. Eine große Zahl von Ursachen können entweder isoliert oder auch synergistisch zur Entwicklung eines C-DRM beitragen ( $\bullet$ Tab. 8).

Eine inadäquate orale Energie- und Proteinaufnahme ist die wichtigste Ursache der Malnutrition. Diese ist vorwiegend auf eine Anorexie zurückzuführen, die wiederum durch eine Akkumulation von urämischen Toxinen, durch die urämische Inflammation, durch Azidose, die Dialysetherapie per se oder durch interkurrente Erkrankungen bedingt ist.

Die Anorexie kann verstärkt werden durch den Gastrointestinaltrakt beeinflussende Begleiterkrankungen, durch psychosoziale Probleme und Depression oder durch einen niedrigen sozioökonomischen Status. 
Tab. 8 Ursachen der C-DRM bei Patienten mit fortgeschrittenen CNI bzw. im Dialysestadium (ESDR/CNI-5) (modifiziert nach [9]).

verminderte orale Protein- und Energieaufnahme
- Anorexie
- Dysregulation der appetitsteuernden Hormone
- geändertes hypothalamisches Hungerempfinden
- stickstoffhaltige urämische Toxine
- diätetische Restriktionen
- Störungen von Organfunktionen, die an der Nahrungsaufnahme
beteiligt sind
- verzögerte Magenentleerung
- Erhöhung des intraabdominellen Druckes (PD)
- psychosoziale Probleme, Depression
- Unfähigkeit, Nahrung zu organisieren oder zuzubereiten
Hypermetabolismus
- erhöhter Energieumsatz
- Inflammation
- gesteigerte Konzentration an proinflammatorischen Zytokinen
- Insulinresistenz als Folge der Adipositas
- Geänderter Adiponectin- und Resistinstoffwechsel
- endokrine Störungen
- Insulinresistenz
- erhöhte Glukokortikoidwirkung
metabolische Azidose
verminderte körperliche Aktivität
beeinträchtigter Anabolismus
- verminderte Nahrungszufuhr
- Resistenz gegenüber HGH/IGF-1
- Testosteronmangel
- erniedrigte Thyroid-Hormon-Spiegel
Begleiterkrankungen und Lebensstilfaktoren
- Komorbiditäten (Diabetes mellitus, Herzinsuffizienz, Depression,
KHK, pAVK etc.)
dialyseassoziierte Faktoren
- Verlust von Nährstoffen
- dialysebedingte Inflammation
- dialysebedingter Hypermetabolismus
- Rückgang der Nierenrestfunktion
-

Bei PD-Patienten kommt es zum frühzeitigen Sättigungsgefühl durch die intraperitoneale Dialysatinfusion und durch die Glukoseresorption aus dem Dialysat.

Zusätzlich erhöhen dialyseassoziierte Verluste von Aminosäuren, Proteinen, Vitaminen und anderen Nährstoffen zusätzlich das Risiko der Entstehung einer C-DRM (s. Tab.8).

Prävention und Therapie der C-DRM müssen darauf zielen, den Verlust des Proteinbestands und der Energiespeicher zu limitieren und den Aufbau funktioneller Körpermasse zu stimulieren. In diesem Kontext kann sowohl in der Vermeidung als auch in der Therapie der C-DRM der künstlichen Ernährung eine wichtige Rolle zukommen. Das Spektrum ernährungsmedizinischer spezifischer Interventionen reicht dabei von der oralen Nahrungssupplementation (ONS) über die enterale Ernährung bis hin zur intradialytischen oder letztendlich totalen parenteralen Ernährung [12].

7.1 Was sind die Ursachen der chronischen krankheitsspezifischen Mangelernährung (C-DRM) bei terminaler Niereninsuffizienz (ESDR; CNI-5)

\section{Statement 13:}

Die chronische krankheitsspezifische Mangelernährung (C-DRM) bei Patienten mit terminaler Niereninsuffizienz (CNI-5, ESRD) hat multiple Ursachen ( $\bullet$ Tab. 8).

\subsection{Wie hoch ist der Nährstoffbedarf von ESRD-Patienten} mit manifester C-DRM?

\section{Statement 14:}

Die Nährstoffzufuhr von Patienten mit terminaler Niereninsuffizienz (CNI-5, ESDR) und manifester chronischer krankheitsspezifischer Mangelernährung (C-DRM) kann in der Regel standardisiert erfolgen ( Tab.9).

Tab.9 Nährstoffbedarf von chronischen ESRD-Patienten unter Nierenersatztherapie*.

\begin{tabular}{|lll|}
\hline Energie & $30-35^{* *}$ & $\mathrm{kcal} / \mathrm{kg} \mathrm{KG} / \mathrm{Tag}$ \\
\hline Protein/Aminosäuren & $1,2-1,4$ & $\mathrm{~g} / \mathrm{kg} \mathrm{KG} / \mathrm{Tag}$ \\
\hline Kohlenhydrate & $3,0-4,0$ & $\mathrm{~g} / \mathrm{kg} \mathrm{KG} / \mathrm{Tag}$ \\
\hline Fett & $0,8-1,2^{* * *}$ & $\mathrm{~g} / \mathrm{kg} \mathrm{KG} / \mathrm{Tag}$ \\
\hline L-Carnitin $^{1}$ & 0,5 & $\mathrm{~g} / \mathrm{Tag}$ \\
\hline wasserlösliche Vitamine $^{2}$ & (Kombinations- & 2-mal Tages- \\
& präparate) & bedarf (RDA) \\
\hline fettlösliche Vitamine & (Kombinations- & 1 -mal Tages- \\
\hline Spurenelemente & präparate) & bedarf (RDA) \\
\hline Elektrolyte* & (Kombinations- & 1 -mal Tages- \\
& präparate) & bedarf (RDA) \\
\hline Flüssigkeit* & Phosphat $800-1000$ & $\mathrm{mg} /$ Tag \\
\hline
\end{tabular}

* Individualisierung! Der Bedarf kann zwischen Patienten sehr unterschiedlich sein, sich aber auch im Krankheitsverlauf grundsätzlich ändern; ** in Abhängigkeit der körperlichen Aktivität; *** Monitoring der Plasmatriglyzeride erforderlich; ${ }^{1}$ optional; ${ }^{2}$ enterale Diätpräparate enthalten den empfohlenen Tagesbedarf

Kommentar: In $\bigcirc$ Tab.9 sind Richtwerte angegeben. Der Substratbedarf für diese Patientengruppen muss individuell an den Patienten adaptiert werden [38].

Cave: Patienten mit ESRD und akuten Begleiterkrankungen bzw. mit einem ausgeprägten inflammatorischen Zustand, haben einen erhöhten Substratbedarf.

ESRD-Patienten unter einer Nierenersatztherapie befinden sich in einem chronisch katabolen Zustand, der verstärkt wird durch den inflammatorischen Stimulus der Dialyse selbst, durch infektiöse und volumenassoziierte Komplikationen.

Der minimale Protein- und Energiebedarf beträgt bei Patienten unter HD- bzw. PD-Therapie 1,2g/kg KG Eiweiß pro Tag und in Abhängigkeit des Ausmaßes an körperlicher Bewegung - 30 $35 \mathrm{kcal} / \mathrm{kg}$ KG/an Energie pro Tag.

Für diese Berechnung kann entweder das tatsächliche, meist erniedrigte oder ein definiertes „Ziel“-Körpergewicht (ideales Körpergewicht) herangezogen werden.

Cave: Häufig ist bei diesen Patienten eine Elektrolytrestriktion (Phosphat, Kalium, Natrium) notwendig. Patienten mit ausgeprägter Malnutrition können jedoch einen Phosphatmangel aufweisen!

\subsection{Welches sind die ernährungstherapeutischen Optionen bei ESRD-Patienten mit C-DRM?}

Das therapeutische Ziel muss sein, den Verlust von funktioneller Körpermasse zu verhindern und die adäquate Zufuhr des Bedarfes an Nährstoffen sicherzustellen. Die therapeutischen Optionen sind in Tab. 10 zusammengefasst.

Patienten unter Nierenersatztherapie und dem Risiko an bzw. mit manifester Malnutrition sollten zunächst diätetisch beraten werden, um eine orale Ernährung zu optimieren. 
Tab. 10 Ernährungstherapeutische Optionen bei chronischen ESRD unter Nierenersatztherapie.

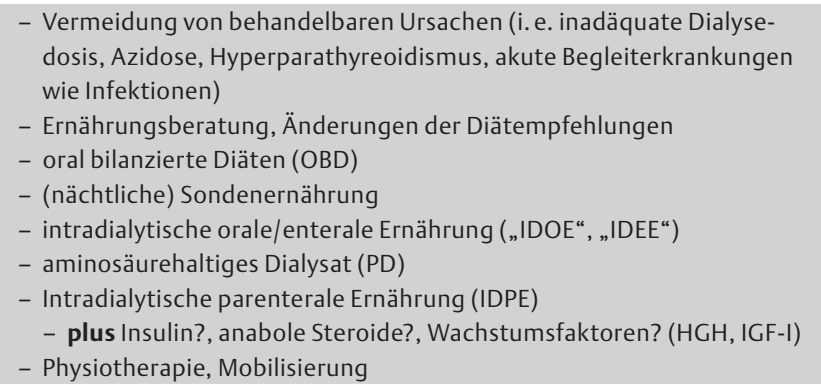

Die nächsten Stufen der Ernährungsbehandlung beinhalten die orale Nahrungssupplementation (ONS) zu Hause, die intradialytische orale/enterale Supplementierung (IDOE, IDEE) und die Kombination mit einer intradialytischen parenteralen Ernährung (IDPN). Die enterale Ernährung mit verschiedenen Sondentechniken und die totale parenterale Ernährung sind ausgewählten Fällen vorbehalten.

Die optimierte Ernährungstherapie kann nur ein Element in der metabolischen Führung dieser Patienten darstellen. Diese muss auch die bei dieser Patientengruppe wesentlichen psychosozialen Probleme berücksichtigen und die meist stark verminderte körperliche Aktivität erhöhen [62]. Dazu gehören aber auch antiinflammatorische Therapiemaßnahmen und die Gabe von anabolen Steroiden, beides derzeit noch Thema von klinischen Studien [63].

Cave: Die positiven Auswirkungen einer Ernährungstherapie korrelieren direkt mit dem Ausmaß der C-DRM und der Menge der verabreichten Nahrung. Eine vorbestehende Inflammation beeinträchtigt nicht den metabolischen Effekt einer optimierten Nährstoffzufuhr. Die Art der Zufuhr (oral/enteral/parenteral) hat keinen wesentlichen Einfluss auf den therapeutischen Erfolg, solange eine ausreichende Menge (Wochendosis!) an Energie und Protein zugeführt wird.

\subsection{Welche zusätzlichen metabolischen Interventionen sollten bei ESRD-Patienten mit C-DRM berücksichtigt werden?}

Die metabolische Führung von Patienten mit CHD-5b/ESRD geht weit über eine reine Nährstoffzufuhr hinaus.

Zusätzliche metabolische Interventionen bei Patienten mit CNI5b/ESRD unter Nierenersatztherapie können sein:

- zieldefinierte Azidosekontrolle

- Appetitanreger

- Wachstumsfaktoren/anabole Steroide

- antiinflammatorische Strategien

- individualisierte Vitaminsubstitution

Diese zusätzlichen Ansatzpunkte für Interventionen sind jedoch nicht Gegenstand dieser Empfehlungen.
7.5 Kann durch orale Nahrungssupplementation (ONS) oder einer enteralen Ernährung bei diesen Patienten der Ernährungszustand verbessert werden?

\section{Statement 15:}

Die regelmäßige orale oder enterale Verabreichung von oral bilanzierten Diäten (OBD) oder Sondennahrung kann bei Patienten mit terminaler Niereninsuffizienz (CNI-5, ESRD) den Ernährungszustand verbessern.

Kommentar: ESRD-Patienten unter Nierenersatztherapie haben ein hohes Risiko eine Malnutrition zu entwickeln und sollten daher grundsätzlich dazu ermutigt werden, ausreichend Nahrung zu essen oder bei schon bestehender Malnutrition oral bilanzierte Diäten (OBD) zu sich zu nehmen.

Die täglich orale Nahrungssupplementation (ONS) ist ein weiterer Schritt in der Therapie der Malnutrition. Dadurch können verschiedene Parameter des Ernährungszustands und der funktionellen Körpermasse günstig beeinflusst werden [17, 64, 65].

Mit oral bilanzierter Diät (OBD), verabreicht 3-mal täglich, kann eine zusätzliche Energiezufuhr von $7-10 \mathrm{kcal} / \mathrm{kg} \mathrm{KG} / \mathrm{Tag}$ und Proteinzufuhr von $0,3-0,4 \mathrm{~g} / \mathrm{kg}$ KG/Tag erzielt werden. Dies wurde sowohl bei Hämodialysepatienten [66] als auch Peritonealdialysepatienten gezeigt [67].

Diese Form der Therapie erfordert daher eine zusätzliche spontane orale Nahrungsaufnahme mit einer Energiezufuhr von 20-25 $\mathrm{kcal} / \mathrm{kg} \mathrm{KG} /$ Tag und Proteinzufuhr von $0,5-0,8 \mathrm{~g} / \mathrm{kg} \mathrm{KG} /$ Tag um die Ernährungsziele (Wochenbedarf) zu decken.

Wenn diese Ziele nicht durch OBD 3-mal täglich erreicht werden können, oder bei Patienten, die nicht schlucken können (mit neurologischen Störungen, in Pflegebereichen), sollte eine Sondenernährung über nasogastrale Sonden oder über eine perkutane endoskopische Gastrostomie (PEG/PEJ) vorgenommen werden, um den Nährstoffbedarf zu decken.

7.6 Kann während der Hämodialyse eine orale Ernährung erfolgen oder eine orale Nahrungssupplementation (ONS) vorgenommen werden?

\section{Empfehlung 23:}

Patienten mit terminaler Niereninsuffizienz (CNI-5, ESRD) und chronischer krankheitsspezifischer Mangelernährung (C-DRM) sollten ermutigt werden, während der Dialysetherapie zu essen (intradialytische orale Ernährung [IDOE]) oder oral bilanzierte Diäten (intradialytische enterale Ernährung [IDEE]) zu sich zu nehmen.

Kommentar: In direktem Gegensatz zu früheren Meinungen, dass eine orale/enterale Ernährung während der Hämodialyse die hämodynamische Stabilität der Therapie negative beeinflussen könnte, besteht heute Übereinstimmung darüber, die Patienten während der Dialysebehandlung zum Essen zu ermutigen (intradialytische orale Ernährung [IDOE]) oder oral bilanzierte Diäten (OBD) zu sich zu nehmen (intradialytische enterale Ernährung [IDEE]) [68].

In metabolischen Isotopenuntersuchungen wurde gezeigt, dass durch eine IDEN der katabole Zustand von Hämodialysepatienten in einen anabolen Zustand überführt werden kann [69-71]. In verschiedenen Langzeituntersuchungen wurde gezeigt, dass durch diese IDEE verschiedene Parameter des Ernährungsstatus, 
der Lebensqualität $[70,71]$ und in einer Beobachtungsstudie auch die Überlebensrate verbessert werden kann [65].

\subsection{Welche Art von Sondennahrungen sollten bei ESRD- Patienten mit C-DRM verwendet werden?}

\section{Empfehlung 24:}

Für Patienten mit terminaler Niereninsuffizienz (CNI-5, ESRD) und chronischer krankheitsspezifischer Mangelernährung (C-DRM) kann die Verwendung von speziell an die Bedürfnisse von Dialysepatienten angepassten Ernährungspräparaten die metabolische Führung erleichtern.

Kommentar: Für stabile Dialysepatienten wurden spezielle Ernährungspräparate für die orale Nahrungssupplementation (ONS) bzw. für die enterale Ernährung entwickelt, die proteinbetont und elektrolytreduziert sind und z.T. spezielle Zusätze enthalten (s. Kapitel 3) [17]. Diese Ernährungspräparate können metabolische Vorteile in der Durchführung der Ernährungstherapie dieser Patientengruppe aufweisen.

Bei Patienten mit hochgradiger Malnutrition und nicht erforderlicher Elektrolytbeschränkung können auch Standarddiäten wie für nicht nierenkranke Personen verwendet werden.

7.8 Welche Besonderheiten gelten für die Gabe von oral bilanzierten Diäten (OBD) oder von enteralen Diäten bei ESRD-Patienten unter Peritonealdialyse?

\section{Empfehlung 25:}

Für Patienten mit mit terminaler Niereninsuffizienz (CNI-5, ESRD) und chronischer krankheitsspezifischer Mangelernährung (CDRM) unter Peritonealdialyse sollten kohlenhydratreduzierte, proteinbetonte Supplemente oder Diäten verwendet werden.

Kommentar: Unter der derzeit üblichen PD-Therapie mit glukosebasierten Dialysatlösungen besteht eine hohe peritoneale Glukoseaufnahme. Andererseits werden über das Peritoneum nicht nur Aminosäuren, sondern auch Proteine und proteingebundene Substanzen, wie Spurenelemente und Vitamine eliminiert. Daher sollten proteinbetonte enterale Ernährungspräparate bzw. Proteinsupplemente eingesetzt und eine ausreichende Zufuhr von Mikronährstoffen sichergestellt werden.

Bei PD mit noch erhaltener Nierenrestfunktion ist das Risiko des Auftretens einer Hyperkaliämie deutlich reduziert, sodass keine speziellen Ernährungspräparate eingesetzt werden müssen.

Zu oraler Nahrungssupplementation (ONS)/enteraler Ernährung bei PD-Patienten sind nur wenige Untersuchungen durchgeführt worden und diese sind mit sehr unterschiedlichen Ernährungspräparaten vorgenommen worden [17]. Insgesamt ist die Toleranz gegenüber einer enteralen Zufuhr in dieser Patientengruppe limitiert. Eine Ursache ist das durch die intraperitoneale Volumenbeladung verstärkte Völlegefühl. Die Drop-out-Rate liegt in einigen Studien bei $>50 \%$.

In einer kontrollierten Studie konnten durch ONS eindrucksvolle Verbesserungen verschiedener Indizes des Ernährungszustands erzielt werden [72].

Im Gegensatz zu Kindern gilt bei Erwachsenen eine PD als Kontraindikation zur Anlage einer PEG. Bei noch im Wachstum befindlichen Kindern wird standardmäßig eine PEG zur supplementierenden Ernährung angelegt.
Alternativ zur enteralen/parenteralen Zufuhr von Proteinen und Aminosäuren sind mit Aminosäuren angereicherte Peritonealdialyselösungen erhältlich. Der Einfluss auf den Ernährungszustand ist jedoch marginal.

\section{9 (Wann) sollte während der Hämodialyse eine parenterale Ernährung vorgenommen werden?}

\section{Empfehlung 26:}

Bei mangelernährten Patienten mit terminaler Niereninsuffizienz (CNI-5, ESRD), bei denen eine orale/enterale Ernährung nicht ausreichend vorgenommen werden kann, sollte die Durchführung einer intradialytischen parenteralen Ernährung (IDPE) erwogen werden.

Kommentar: Obwohl eine orale/enterale Nahrungszufuhr wenn immer möglich angestrebt werden sollte, kann in ausgewählten Fällen, bei denen dies nicht (ausreichend) möglich ist, die wöchentliche Nährstoffzufuhr durch eine intradialytische parenterale Ernährung (IDPE) verbessert werden. Dabei handelt es sich um eine einfache, sichere und durch die Compliance der Patienten nicht beeinflusste Form der Nährstoffzufuhr.

Durch eine IDPE kann der Katabolismus während der Hämodialysetherapie in eine anabole Situation überführt werden [73-75]. Zahlreiche nicht randomisierte Studien haben gezeigt, dass durch eine IDPE verschiedene Indikatoren des Ernährungszustands, der Immunkompetenz, der Lebensqualität und in Beobachtungsstudien auch die Überlebensrate verbessert werden kann $[22,73,75]$.

In einer prospektiven Studie zur IDPE, in der diese zusätzlich zur basalen Zufuhr von oralen Supplementen verabreicht wurde, konnte allerdings kein Überlebensvorteil nachgewiesen werden [76]. Jedoch haben in dieser Studie jene Patienten, die mit den Prä-Albumin-Spiegeln positiv auf die erhöhte Nahrungszufuhr reagiert hatten, einen verbesserten Outcome.

\subsection{Wie sollte eine IDPE zusammengesetzt sein?}

\section{Empfehlung 27:}

Eine intradialytische parenterale Ernährung (IDPN) sollte pro Dialysebehandlung mindestens $0,5 \mathrm{~g} / \mathrm{kg}$ KG Aminosäuren zuführen und etwa $500-800 \mathrm{kcal}$ enthalten.

Kommentar: Eine IPDE ist immer ein Kompromiss. Bedingt durch die Kürze des Verabreichungszeitraums einer Dialysebehandlung muss die mögliche Nährstoffzufuhr limitiert werden, um metabolische Entgleisungen zu vermeiden.

Eine allgemein anerkannte optimale Zusammensetzung einer IDPE gibt es nicht. Mit einer IDPE können 0,5-0,75g Aminosäuren/kg KG und bis $800 \mathrm{kcal}$ pro Behandlung verabreicht werden. Die Zufuhr an Glukose ist auf 50 - 80 g, die von Fetten auf 20-30 g pro HD zu limitieren. Die isolierte Zufuhr eines einzigen Nährstoffs (z.B. Aminosäuren) ist nicht zu empfehlen.

Das IDPE-Ernährungsziel kann am ehesten durch Verwendung einer Gesamtnährlösung erreicht werden, die Aminosäuren, Glukose und Fett in einem Beutel enthält. Dazu können entweder kommerziell erhältliche Fertiglösungen eingesetzt werden oder auch patientenbezogene Lösungen von Compounding-Firmen bezogen werden. Nach Bedarf können der Lösung auch wasserlösliche und fettlösliche Vitamine oder auch Carnitin oder bei Hy- 
pophosphatämie auch Phosphat (organisches Phosphat) zugesetzt werden.

Manche Gruppen setzten der Nährlösung - auch wenn kein Diabetes mellitus besteht - geringe Mengen an Insulin (z.B. 4 E) zu, um den anabolen Effekt der Aminosäuren zu verbessern [77]. Unter dieser geringen Insulindosis besteht keine Gefahr der Auslösung einer Hypoglykämie.

Wenn bei diesen Patienten eine parenterale Ernährung notwendig wird, gelten die zuvor formulierten Statements (s. o.).

\section{Interessenkonflikt}

$\nabla$

Gemäß den AWMF-Richtlinien wurden die bestehenden potenziellen Interessenkonflikte zu Beginn der Leitlinienarbeit von allen Autoren bzw. Arbeitsgruppenmitgliedern dargelegt. Die Autoren/Arbeitsgruppenmitglieder haben bei folgenden Punkten entsprechende Angaben gemacht:

Berater- bzw. Gutachtertätigkeit oder Mitglied eines wissenschaftlichen Beirats eines Unternehmens: W. Druml, M. Kuhlmann, S. C. Bischoff, H. Lochs.

Vortragshonorare von Unternehmen: W. Druml, H. Kierdorf, M. Kuhlmann, S. C. Bischoff, H. Lochs, A. Weimann.

Finanzielle Zuwendungen für Forschungsvorhaben vonseiten eines Unternehmens: W. Druml, S. C. Bischoff, A. Weimann.

Die anderen Autoren haben keinen Interessenkonflikt.

Einzelheiten sind im Leitlinienreport des Leitlinien-Updates Klinische Ernährung, der über die Internetseite der AWMF abrufbar ist, hinterlegt.

Institute

Allgemeines Krankenhaus Wien, Klinik für Innere Medizin II, Abteilung für Nephrologie, Wien, Österreich

2 Selbstständig, Köln, Deutschland

3 Universitätsklinik für Innere Medizin, Gemeinsame Einrichtung Internistische Intensiv- und Notfallmedizin, Innsbruck, Österreich

${ }^{4}$ Klinikum Braunschweig, Klinik für Nieren- und Hochdruckkrankheiten (Medizinische Klinik V), Braunschweig, Deutschland

5 Vivantes Klinikum im Friedrichshain, Innere Medizin - Nephrologie, Berlin, Deutschland

\section{Literaturverzeichnis}

1 Li Y, Tang $X$, Zhang J et al. Nutritional support for acute kidney injury. Cochrane Database Syst Rev 2012; 8: CD005426

2 Cano NJ, Aparicio M, Brunori G et al. ESPEN Guidelines on Parenteral Nutrition: adult renal failure. Clin Nutr 2009; 28: $401-414$

3 Fiaccadori E, Cremaschi E, Regolisti G. Nutritional assessment and delivery in renal replacement therapy patients. Semin Dial 2011; 24: $169-175$

4 Druml $W$. Nutrition and renal insufficiency. Med Klin Intensivmed Notfmed 2013; 108: 384-390

5 Druml W, Kuhlmann M, Mann H et al. DGEM-Leitlinie Enterale Ernährung: Nephrologie. Aktuel Ernahrungsmed 2003; 28: 93-102

6 Druml W, Kierdorf H. Leitlinie Parenterale Ernährung der DGEM - 17. Nierenversagen. Aktuel Ernahrungsmed 2007; 32: 106-113

7 Cano N, Fiaccadori E, Tesinsky P et al. DGEM (German Society for Nutritional Medicine). ESPEN Guidelines on Enteral Nutrition: Adult renal failure. Clin Nutr 2006; 25: 295-310

8 Fouque D, Kalantar-Zadeh K, Kopple J et al. A proposed nomenclature and diagnostic criteria for protein-energy wasting in acute and chronic kidney disease. Kidney Int 2008; 73: 391 - 398

9 Carrero JJ, Stenvinkel P, Cuppari $L$ et al. Etiology of the protein-energy wasting syndrome in chronic kidney disease: a consensus statement from the International Society of Renal Nutrition and Metabolism (ISRNM). J Ren Nutr 2013; 23: 77-90
10 Metnitz GH, Fischer M, Bartens $C$ et al. Impact of acute renal failure on antioxidant status in multiple organ failure. Acta Anaesthesiol Scand 2000; 44: $236-240$

11 Himmelfarb J, McMonagle E, Freedman $S$ et al. Oxidative stress is increased in critically ill patients with acute renal failure. J Am Soc Nephrol 2004; 15: 2449-2456

12 Ikizler TA, Cano NJ, Franch $\mathrm{H}$ et al. Prevention and treatment of protein energy wasting in chronic kidney disease patients: a consensus statement by the International Society of Renal Nutrition and Metabolism. Kidney Int 2013; 84: 1096-1107

13 Schneeweiss B, Graninger W, Stockenhuber $F$ et al. Energy metabolism in acute and chronic renal failure. Am J Clin Nutr 1990; 52: 596-601

14 Singer P, Berger MM, Van den Berghe $G$ et al. ESPEN Guidelines on Parenteral Nutrition: intensive care. Clin Nutr 2009; 28: 387-400

15 Mouser JF, Hak EB, Kuhl DA et al. Recovery from ischemic acute renal failure is improved with enteral compared with parenteral nutrition. Crit Care Med 1997; 25: 1748 - 1754

16 Metnitz PG, Krenn CG, Steltzer $H$ et al. Effect of acute renal failure requiring renal replacement therapy on outcome in critically ill patients. Crit Care Med 2002; 30: 2051 - 2058

17 Kalantar-Zadeh K, Cano NJ, Budde K et al. Diets and enteral supplements for improving outcomes in chronic kidney disease. Nat Rev Nephrol 2011; 7: 369-384

18 Krishnamurthy VM, Wei G, Baird BC et al. High dietary fiber intake is associated with decreased inflammation and all-cause mortality in patients with chronic kidney disease. Kidney Int 2012; 81: 300-306

19 Fiaccadori E, Maggiore U, Giacosa $R$ et al. Enteral nutrition in patients with acute renal failure. Kidney Int 2004; 65: 999-1008

20 Ross EA, Koo LC. Improved nutrition after the detection and treatment of occult gastroparesis in nondiabetic dialysis patients. Am J Kidney Dis 1998; 31: 62-66

21 Smolle KH, Kaufmann P, Fleck S et al. Influence of a novel amino acid solution (enriched with the dipeptide glycyl-tyrosine) on plasma amino acid concentration of patients with acute renal failure. Clin Nutr 1997; 16: $239-246$

22 Czekalski S, Hozejowski R. Malnutrition Working Group. Intradialytic amino acids supplementation in hemodialysis patients with malnutrition: results of a multicenter cohort study. J Ren Nutr 2004; 14: $82-88$

23 Roth E, Druml W. Plasma amino acid imbalance: dangerous in chronic diseases? Curr Opin Clin Nutr Metab Care 2011; 14: 67 - 74

$24 \mathrm{Hu}$ YM, Pai MH, Yeh $\mathrm{CL}$ et al. Glutamine administration ameliorates sepsis-induced kidney injury by downregulating the high-mobility group box protein-1-mediated pathway in mice. Am J Physiol Renal Physiol 2012; 302: F150-158

25 Heyland D, Muscedere J, Wischmeyer PE et al. A randomized trial of glutamine and antioxidants in critically ill patients. N Engl J Med 2013; 368: $1489-1497$

26 Heyland DK, Elke G, Cook D et al. Glutamine and Antioxidants in the Critically Ill Patient: A Post Hoc Analysis of a Large-Scale Randomized Trial. JPEN J Parenter Enteral Nutr 2014: May 5. [Epub ahead of print]

27 Druml W, Fischer $M$, Sertl $S$ et al. Fat elimination in acute renal failure: long-chain vs medium-chain triglycerides. Am J Clin Nutr 1992; 55: 468-472

28 Chou HH, Chiou YY, Hung PH et al. Omega-3 fatty acids ameliorate proteinuria but not renal function in IgA nephropathy: a meta-analysis of randomized controlled trials. Nephron Clin Pract 2012; 121: c30 - 35

29 Wang X, Li W, Li N et al. Omega-3 fatty acids-supplemented parenteral nutrition decreases hyperinflammatory response and attenuates systemic disease sequelae in severe acute pancreatitis: a randomized and controlled study. JPEN J Parenter Enteral Nutr 2008; 32: 236-241

30 Basi S, Pupim LB, Simmons EM et al. Insulin resistance in critically ill patients with acute renal failure. Am J Physiol Renal Physiol 2005; 289: F259-264

31 Schetz M, Vanhorebeek I, Wouters PJ et al. Tight blood glucose control is renoprotective in critically ill patients. J Am Soc Nephrol 2008; 19: $571-578$

32 Aspelin P, Mac Leod A, Barsoum R et al. KDIGO Clinical Practice Guideline for Acute Kidney Injury. Kidney Int Suppl 2012; 2: 1-138

33 Fouque $D$, Laville M. Low protein diets for chronic kidney disease in non diabetic adults. Cochrane Database Syst Rev 2009: (03): CD001892 Doi: CD001892

34 Navaneethan SD, Schold JD, Arrigain $S$ et al. Serum bicarbonate and mortality in stage 3 and stage 4 chronic kidney disease. Clin J Am Soc Nephrol 2011; 6: 2395-2402 
35 Susantitaphong P, Sewaralthahab K, Balk EM et al. Short- and long-term effects of alkali therapy in chronic kidney disease: a systematic review. Am J Nephrol 2012; 35: 540 - 547

36 Abramowitz MK, Melamed ML, Bauer $C$ et al. Effects of oral sodium bicarbonate in patients with CKD. Clin J Am Soc Nephrol 2013; 8: $714-720$

37 Goraya N, Simoni J, Jo $\mathrm{CH}$ et al. Treatment of metabolic acidosis in patients with stage 3 chronic kidney disease with fruits and vegetables or oral bicarbonate reduces urine angiotensinogen and preserves glomerular filtration rate. Kidney Int 2014; 86: 1031 - 1038

38 Fouque D, Pelletier S, Mafra $D$ et al. Nutrition and chronic kidney disease. Kidney Int 2011; 80: 348 - 357

39 Druml W. Metabolic aspects of continuous renal replacement therapies. Kidney Int Suppl 1999: (72): S56-S61

40 Ikizler TA, Pupim LB, Brouillette JR et al. Hemodialysis stimulates muscle and whole body protein loss and alters substrate oxidation. Am J Physiol Endocrinol Metab 2002; 282: E107-116

41 Fiaccadori E, Maggiore $U$, Cabassi $A$ et al. Nutritional evaluation and management of AKI patients. J Ren Nutr 2013; 23: 255 - 258

42 Fiaccadori E, Maggiore $U$, Rotelli $C$ et al. Effects of different energy intakes on nitrogen balance in patients with acute renal failure: a pilot study. Nephrol Dial Transplant 2005; 20: 1976-1980

43 Bellomo R, Tan HK, Bhonagiri S et al. High protein intake during continuous hemodiafiltration: impact on amino acids and nitrogen balance. Int J Artif Organs 2002; 25: 261 - 268

44 Scheinkestel $C D$, Adams F, Mahony $L$ et al. Impact of increasing parenteral protein loads on amino acid levels and balance in critically ill anuric patients on continuous renal replacement therapy. Nutrition 2003 19: $733-740$

45 Leblanc M, Garred LJ, Cardinal J et al. Catabolism in critical illness: estimation from urea nitrogen appearance and creatinine production during continuous renal replacement therapy. Am J Kidney Dis 1998; 32: $444-453$

46 Bellomo $R$, Cass A, Cole $L$ et al. Daily Protein Intake and Patient Outcomes in Severe Acute Kidney Injury: Findings of the Randomized Evaluation of Normal versus Augmented Level of Replacement Therapy (RENAL) Trial. Blood Purif 2014; 37: 325 - 334

47 Singer $P$. High-dose amino acid infusion preserves diuresis and improves nitrogen balance in non-oliguric acute renal failure. Wien Klin Wochenschr 2007; 119: 218-222

48 Schiffl H, Lang SM. Severe acute hypophosphatemia during renal replacement therapy adversely affects outcome of critically ill patients with acute kidney injury. Int Urol Nephrol 2013; 45: 191-197

49 Demirjian S, Teo BW, Guzman JA et al. Hypophosphatemia during continuous hemodialysis is associated with prolonged respiratory failure in patients with acute kidney injury. Nephrol Dial Transplant 2011; 26: $3508-3514$

50 Broman $M$, Carlsson 0 , Friberg $H$ et al. Phosphate-containing dialysis solution prevents hypophosphatemia during continuous renal replacement therapy. Acta Anaesthesiol Scand 2011; 55: 39-45

51 Fortin MC, Amyot SL, Geadah D et al. Serum concentrations and clearances of folic acid and pyridoxal-5-phosphate during venovenous continuous renal replacement therapy. Intensive Care Med 1999; 25 : $594-598$

52 Morena M, Cristol JP, Bosc JY et al. Convective and diffusive losses of vitamin $C$ during haemodiafiltration session: a contributive factor to oxidative stress in haemodialysis patients. Nephrol Dial Transplant 2002; $17: 422-427$

53 Madl C, Kranz A, Liebisch B et al. Lactic acidosis in thiamine deficiency. Clin Nutr 1993; 12: 108-111

54 Druml W, Schwarzenhofer M, Apsner R et al. Fat-soluble vitamins in patients with acute renal failure. Miner Electrolyte Metab 1998; 24: $220-226$

55 Amrein K, Schnedl C, Holl A et al. Effect of high-dose vitamin D3 on hospital length of stay in critically ill patients with vitamin D deficiency: the VITdAL-ICU randomized clinical trial. JAMA 2014; 312: 1520 1530

56 Lipkin AC, Lenssen P. Hypervitaminosis a in pediatric hematopoietic stem cell patients requiring renal replacement therapy. Nutr Clin Pract 2008; 23: $621-629$
57 Berger MM, Shenkin A, Revelly JP et al. Copper, selenium, zinc, and thiamine balances during continuous venovenous hemodiafiltration in critically ill patients. Am J Clin Nutr 2004; 80: 410-416

58 Heidegger CP, Berger MM, Graf S et al. Optimisation of energy provision with supplemental parenteral nutrition in critically ill patients: a randomised controlled clinical trial. Lancet 2013; 381: 385 - 393

59 Gunst J, Vanhorebeek I, Casaer MP et al. Impact of early parenteral nutrition on metabolism and kidney injury. J Am Soc Nephrol 2013; 24: 995- 1005

60 Doig GS, Simpson F, Sweetman EA et al. Early parenteral nutrition in critically ill patients with short-term relative contraindications to early enteral nutrition: a randomized controlled trial. JAMA 2013; 309: $2130-2138$

61 Griffiths RD, Jones C, Palmer TE. Six-month outcome of critically ill patients given glutamine-supplemented parenteral nutrition. Nutrition 1997; 13: 295-302

62 Majchrzak KM, Pupim LB, Flakoll PJ et al. Resistance exercise augments the acute anabolic effects of intradialytic oral nutritional supplementation. Nephrol Dial Transplant 2008; 23: 1362 -1369

63 Johansen KL, Mulligan K, Schambelan M. Anabolic effects of nandrolone decanoate in patients receiving dialysis: a randomized controlled trial JAMA 1999; 281: 1275-1281

64 Kuhlmann MK, Schmidt F, Kohler H. High protein/energy vs. standard protein/energy nutritional regimen in the treatment of malnourished hemodialysis patients. Miner Electrolyte Metab 1999; 25: 306 - 310

65 Weiner DE, Tighiouart $H$, Ladik $V$ et al. Oral intradialytic nutritional supplement use and mortality in hemodialysis patients. Am J Kidney Dis 2014; 63: 276-285

66 Stratton RJ, Bircher G, Fouque D et al. Multinutrient oral supplements and tube feeding in maintenance dialysis: a systematic review and meta-analysis. Am J Kidney Dis 2005; 46: 387-405

67 Boudville N, Rangan A, Moody H. Oral nutritional supplementation increases caloric and protein intake in peritoneal dialysis patients. Am J Kidney Dis 2003; 41: 658-663

68 Kalantar-Zadeh K, Ikizler TA. Let them eat during dialysis: an overlooked opportunity to improve outcomes in maintenance hemodialysis patients. J Ren Nutr 2013; 23: 157 - 163

69 Pupim LB, Flakoll PJ, Brouillette JR et al. Intradialytic parenteral nutrition improves protein and energy homeostasis in chronic hemodialysis patients. J Clin Invest 2002; 110: $483-492$

70 Fouque D, McKenzie J, de Mutsert $R$ et al. Use of a renal-specific oral supplement by haemodialysis patients with low protein intake does not increase the need for phosphate binders and may prevent a decline in nutritional status and quality of life. Nephrol Dial Transplant 2008; 23: $2902-2910$

71 Lacson E Jr, Wang W, Zebrowski B et al. Outcomes associated with intradialytic oral nutritional supplements in patients undergoing maintenance hemodialysis: a quality improvement report. Am J Kidney Dis 2012; 60: $591-600$

72 Teixido-Planas J, Ortiz A, Coronel F et al. Oral protein-energy supplements in peritoneal dialysis: a multicenter study. Perit Dial Int 2005; 25: $163-172$

73 Smolle KH, Kaufmann P, Holzer $H$ et al. Intradialytic parenteral nutrition in malnourished patients on chronic haemodialysis therapy. Nephrol Dial Transplant 1995; 10: 1411 - 1416

74 Pupim LB, Majchrzak KM, Flakoll PJ et al. Intradialytic oral nutrition improves protein homeostasis in chronic hemodialysis patients with deranged nutritional status. J Am Soc Nephrol 2006; 17: 3149-3157

75 Dukkipati R, Kalantar-Zadeh K, Kopple JD. Is there a role for intradialytic parenteral nutrition? A review of the evidence. Am J Kidney Dis 2010; 55: $352-364$

76 Cano NJ, Fouque D, Roth $\mathrm{H}$ et al. Intradialytic parenteral nutrition does not improve survival in malnourished hemodialysis patients: a 2-year multicenter, prospective, randomized study. J Am Soc Nephrol 2007; 18: $2583-2591$

77 Lim VS, Yarasheski KE, Crowley JR et al. Insulin is protein-anabolic in chronic renal failure patients. J Am Soc Nephrol 2003; 14: 2297-2304 